Review

\title{
Systematic Review of Exoskeletons towards a General Categorization Model Proposal
}

\author{
Javier A. de la Tejera ${ }^{1, * \mathbb{C}}$, Rogelio Bustamante-Bello ${ }^{1} \mathbb{C}$, Ricardo A. Ramirez-Mendoza ${ }^{1, *(\mathbb{C}}$ \\ and Javier Izquierdo-Reyes ${ }^{1,2}$ \\ 1 School of Engineering and Sciences, Tecnologico de Monterrey, Mexico City 14380, Mexico; \\ rbustama@tec.mx (R.B.-B.); jizquierdo.reyes@tec.mx or javieriz@mit.edu (J.I.-R.) \\ 2 Microsystems Technology Laboratories, Massachusetts Institute of Technology, Cambridge, MA 02319, USA \\ * Correspondence: j.delatejera@tec.mx (J.A.d.1.T.); ricardo.ramirez@tec.mx (R.A.R.-M.)
}

\section{check for}

updates

Citation: de la Tejera, J.; Bustamante, R.; Ramirez, R.; Izquierdo, J. Systematic Review of Exoskeletons towards a General Categorization Model Proposal. Appl. Sci. 2021, 11, 76. https://dx.doi. org/10.3390/app11010076

Received: 1 December 2020

Accepted: 10 December 2020

Published: 24 December 2020

Publisher's Note: MDPI stays neutral with regard to jurisdictional claims in published maps and institutional affiliations.

Copyright: (c) 2020 by the authors. Licensee MDPI, Basel, Switzerland. This article is an open access article distributed under the terms and conditions of the Creative Commons Attribution (CC BY) license (https: / / creativecommons.org/ licenses/by/4.0/).

\begin{abstract}
Exoskeletons are an essential part of humankind's future. The first records regarding the subject were published several decades ago, and the field has been expanding ever since. Their developments will be imperative for humans in the coming decades due to our constant pursuit of physical enhancement, and the physical constraints the human body has. The principal purpose of this article is to formalize research in the field of exoskeletons and introduce the field to more researchers in hopes of expanding research in the area. Exoskeletons can assist and/or aid in the rehabilitation of a person. Recovery exoskeletons are mostly used in medical and research areas; performance exoskeletons can be used in any area. This systematic review explains the precedents of the exoskeletons and gives a general perspective on their general present-day use, and provides a general categorization model with a brief description of each category. Finally, this paper provides a discussion of the state-of-the-art, and the current control techniques used in exoskeletons.
\end{abstract}

Keywords: exoskeletons; bioengineering; biomechanics; biomechatronics; rehabilitation robotics

\section{Introduction}

In the modern era, humanity is in constant pursuit of the improvement of everything the world, including improvement of itself. As technology evolves, humanity evolves with it in a systematic, artificial way. One of the strategies to attain such improvements is in the area of exoskeletons. Exoskeletons are orthoses of a certain kind-devices that work in harmony and parallel with their users in order to augment physical performance [1] and are able to complete certain tasks or movements. In order to achieve such coordination, the device must be fitted to the user's dimensions [1].

While in other research areas, exoskeletons are used for protection [2], on humans, their main use is the augmentation of the physical capabilities. This article will only refer to exoskeletons for human use.

This article contains information about several aspects of exoskeletons, for this reason, a graphical abstract is presented to show the structure of this article.

The exoskeletons' limits are set only by the state of current technology and human imagination. This means that, with the previous definition, the exoskeletons can be used in any physical activity of a person. However, these constraints keep this research field from being fully exploited to improve the life quality of people. Nevertheless, the current development of exoskeletons is historically growing, creating the necessity to formalize this research field to accelerate the current developments.

With the necessity of formalizing this research field, and the wide variety of possibilities of exoskeletons, the requirement to differentiate between each exoskeleton, using their design characteristics, is needed.

One way to categorize exoskeletons is according to their structure (soft or rigid). A rigid exoskeleton is defined in the literature as an exoskeleton with a structure made of rigid con- 
struction materials, such as metal or plastic, in contrast to a soft exoskeleton which is a structure made of textiles [3], also called an exo-suit.

Furthermore, other exoskeletons may be classified according to the type of action (active or passive). An exoskeleton can have active action if is powered by actuators or passive action if powered by mechanical systems-springs, dampers, etc. [4].

Moreover, another way to categorize exoskeletons is by the technology powering them. Some exoskeletons are hybrids, defined as having a combination of two or more distinct [5] technologies powering the exoskeleton, such as the exoskeletons in [6-8]. The next categorization is according to its purpose, which could be to assist (performance exoskeletons) and/or rehabilitate (recovery exoskeletons-rehabilitation being defined as the restoration by therapeutic means to an improved condition of physical function [9]). Assistance is the act of helping or assisting someone [10]. The kind of help given by an exoskeleton could vary from one to another.

The following sections will present the development of exoskeletons through time, spanning from the late 19th century until present day.

\subsection{Antique Exoskeletons}

Two of the most antique exoskeletons date back to the 19th century in the former Russian Empire by Nicholas Yagn. These devices were called "apparatus for facilitating walking, running, and jumping" and "apparatus to facilitate walking and running" [11,12]. These exoskeletons are some of the oldest designs, if not the oldest, in the world. Their modes of function were merely mechanical, using springs and a unique design to redistribute the energy given by the user while moving. The objective of both devices was to decrease the fatigue of a person walking, running, or jumping [11].

This set the starting point for modern exoskeletons. Even though their designs are not used in the modern times, the principle upon which they were built, the facilitation of tasks, lives on in present-day exoskeletons.

Another invention was created following Yagn's principle at the beginning of the 20th century. Lesley C. Kelley designed a device that was focused on facilitating walking and running, while relieving the strain and fatigue for the muscles used [13]. This design was much smaller than Yagn's design, although this also limited the number of activities it could facilitate.

Throughout the 60s, further exoskeleton designs were developed. Financed by General Electric and the US Army-Navy in 1965, the "Hardiman I" was created, a full-body powered exoskeleton designed to augment the strength and endurance of the user. This system was powered by hydraulic and electrical systems [14].

The "Hardiman I" was not the only exoskeleton to be invented at the time; there was another full-body powered exoskeleton made by Neil J. Mizen, as part of the Cornell Aeronautical Laboratory. This exoskeleton was powered by electromechanical actuators, specifically servo-motors, that responded to a person's normal movement and amplified their capabilities [15].

As there was more technology at the time, the exoskeleton created did not resemble its predecessors. The 60s marked a turning point in exoskeleton development. The advancements were built upon the foundation that was already established by previous models and influenced by science fiction. Iterations that were built after this period maintained certain elements but combined them with emerging technologies of the time.

In the following decades, the advances made in science and technology allowed for further improvements in the area. Thus, in the 70s, 80s, and 90s a wide variety of exoskeletons was developed, each one with a specific use. In the late 70 s and early 80 s, an arm exoskeleton was developed, consisting of a mobile arm support prototype that helped with shoulder and elbow movement, and in certain cases, improved muscular strength and was used in rehabilitation [16]. This device was classified as an orthosis focused on supporting the arm. Nevertheless, this specific orthosis is also an exoskeleton powered by a pneumatic system, making it an active exoskeleton. 
In the late 80s, a similar device to Yagn's was made and patented. The "Mechanical Leg-Propulsion Assistance Device" was similar to Yagn's device, as they shared objectives and a general mode of operation. This device was a leg-propulsion assistance device provided by mechanical systems that worked in combination with the movement of the user [17]. This device can be classified as an exoskeleton focused on the lower limbs, due to the improvement of the physical performance of a person's legs. This device can also be defined as a passive action exoskeleton, due to the mechanical systems that allow the system to operate.

The "Human Bipedal Locomotion Device" was invented at the beginning of the 90s. This device was intended to be worn on the whole body, even though it only focused on the lower limbs. Propelled by mechanical systems, specifically springs, this device was designed to assist a person while walking or running, allowing the user to have large steps or do trampoline-like jumps [18].

In the mid-90s another full-body exoskeleton was created, using hydraulic systems to power the movement and a microprocessor to control the actuators. This design is an example of an exoskeleton with a performance purpose [19]. This exoskeleton exemplifies how, over the years, exoskeletons evolve with the development of new technologies.

The previous exoskeletons are presented in the following chronological timeline in Figure 1.

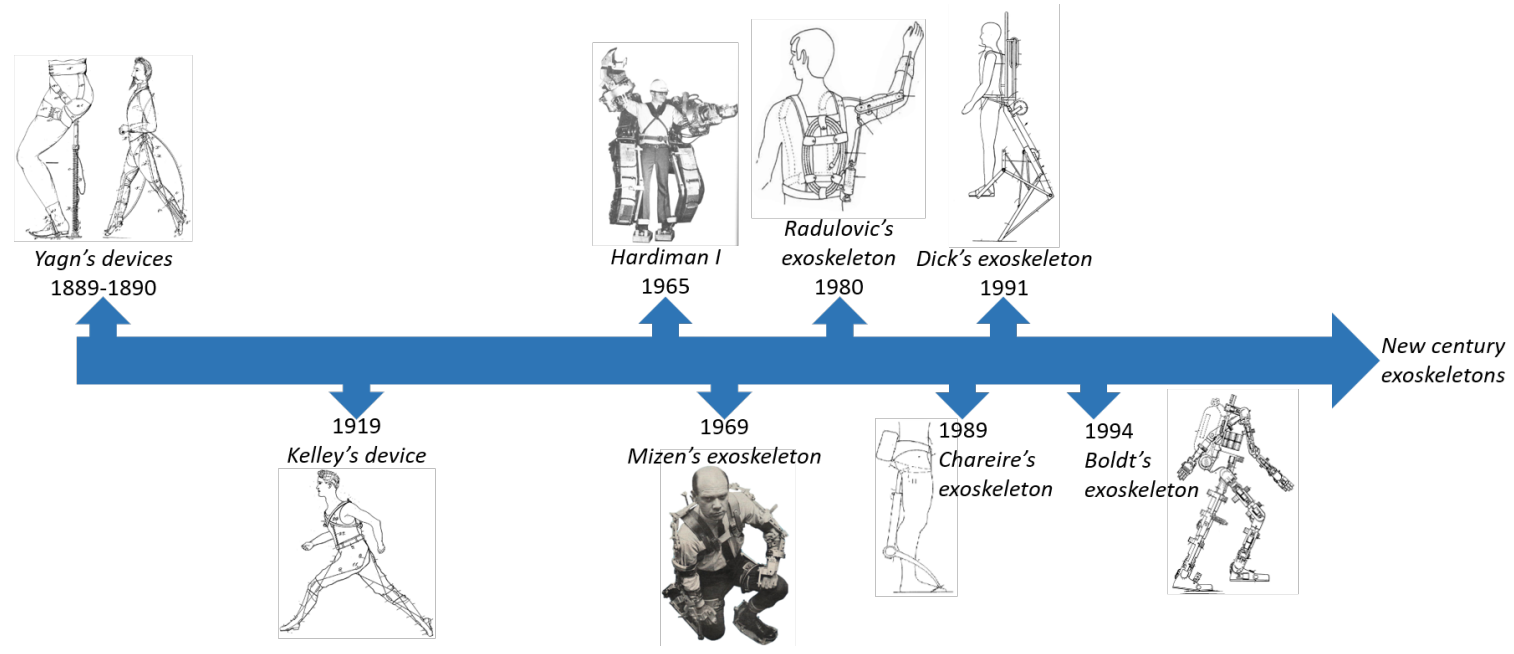

Figure 1. Antique exoskeletons presented chronologically [11-19].

\subsection{New Century Exoskeletons}

In the 21st century, the development of computers and new dedicated software boosted research in many fields. The exoskeleton field was benefited positively, as the access to new technologies increased, such as modeling and simulating software.

The Berkeley Lower Extremity Exoskeleton (BLEEX) demonstrated the advances previously discussed. Originally, the BLEEX project was a lower limb exoskeleton capable of carrying an external load in addition to the exoskeleton's weight. Furthermore, due to the hydraulic actuators and control scheme, this exoskeleton was capable of supporting $75 \mathrm{~kg}$ [20], as seen in the left part of Figure 2. The complete design of the BLEEX exoskeleton was made with CAD software, providing a way of displaying each piece of the exoskeleton and allowing for an error correction phase before the manufacturing. This allowed the saving of time and resources by preventing the manufacturing of faulty prototypes.

The BLEEX set the precedent of the exoskeletons capable of carrying an external load. In the following years the carrying of an external load became the main concern of exoskeleton development. An important design for said purpose was the quasi-passive leg exoskeleton for load-carrying augmentation. This was a lower limb exoskeleton that transferred most of the payload applied. The exoskeleton was made with mechanical systems and the validation of its performance was done by measuring the rate of oxygen 
consumption of the user. The experimental rate was compared to the measures of a similar exoskeleton, in order to validate its performance [21]. This design can be appreciated in the center of Figure 2.

The modern technology of the 21st century also brought improvements to exoskeleton design, allowing for the possibility of designing more personalized exoskeletons, focused on specific pathologies or movements intended by the user instead of the all-inone exoskeletons. The "Motion Assisting Device" is an example of such specific designs. The design is supported only in the waist and thigh, propelling the movement through the thigh support and the actuator between both supports [22], as seen in the right part of Figure 2 .
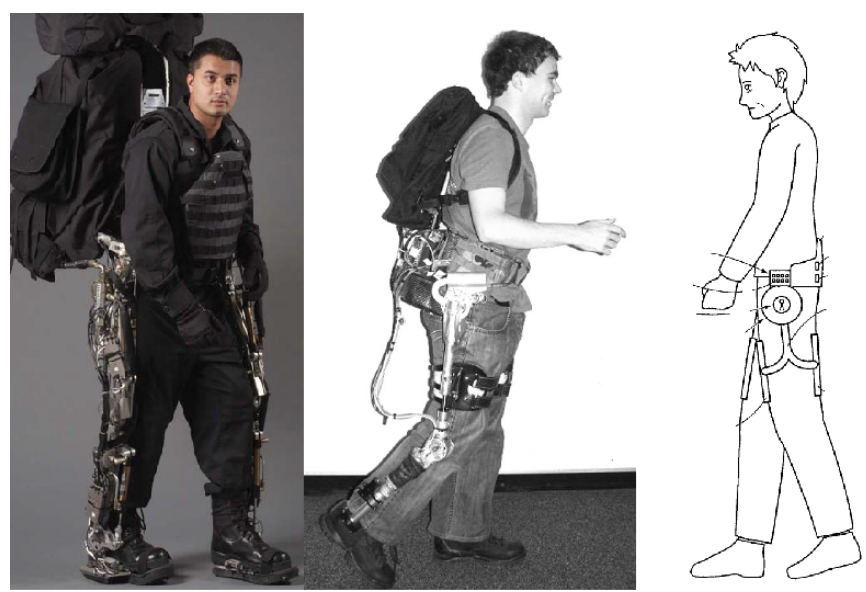

Figure 2. BLEEX Exoskeleton (left) [20], the quasi-passive exoskeleton (center) [21], and the "Motion Assisting Device" [22].

Until now, we have only mentioned the older exoskeletons along with a few more modern ones in order to highlight how the exoskeletons have been evolving alongside to technology. From 2010 to 2015, 3147 book sections, journal articles, and conference articles concerning exoskeletons, indexed in Scopus ${ }^{\circledR}$, were published. Moreover, from 2016 to 2020-07-07, this number increased, reaching 5244 book sections, journal articles, and conference articles concerning the exoskeletons indexed in Scopus ${ }^{\circledR}$. These statistics show an increasing tendency of working with exoskeletons and implementing the newest technologies available to their designs.

However, with all these works regarding exoskeletons, there are some that can be described more easily than others. Thus, it is necessary to classify the exoskeletons according to their design characteristics. The intention of this review is to provide a model with which to classify any exoskeleton. Before that, a review of the state-of-the-art literature is presented. In the following section, the review methodology, used to find the state-of-the-art of exoskeletons, will be described.

\section{Review Methodology}

This section contains the criteria used during the research for the systematic review. Additionally, Figure 3 demonstrates the structure followed while searching for works related to exoskeletons. To have a proper classification for the exoskeletons, first, we need to separate the exoskeletons into certain known classes, such as performance and recovery. From there, the search began with different documents, such as journal or conference articles (for research), patents, and news of exoskeletons that are products. The news was used to find such exoskeletons and their corresponding companies' web pages. 




Figure 3. Structure followed in the Review Methodology section to find the exoskeletons used in this work.

\subsection{Inclusion Criteria}

All peer-reviewed journal and conference proceeding articles, patents, and web pages were published in or translated to English; are directly or indirectly related to assistance, performance, recovery, or rehabilitation exoskeletons; and are in a research, patent, or product phase.

\subsection{Exclusion Criteria}

The criteria of exclusion for this review were minimal, as any state-of-the-art exoskeleton could be used. The exclusion criteria in this review included: exoskeletons that did not go through a peer-review process for publication, were not patented, or are not products published on their respective companies' web pages; also, exoskeletons published in a nonEnglish languages and those whose translations to English were very poor, exoskeletons whose their basic characteristics cannot be known, and exoskeletons released before 2014 .

\subsection{Information Databases and Search Methodology}

The following electronic bibliographic databases were used: ACM, BioMed Central, Elsevier, Frontiers in neuroscience, Google Patents, IEEE, IOS Press, Nature, SAGE, Science, and Springer. Articles were found using the keyword "exoskeleton," and we derived combination sets with the following words: assistance, rehabilitation, soft, lower limb, upper limb, full-body, active, passive, cost reduction, electrical, pneumatic, hydraulic, and mechanical. The date range established was between 2014 and 2020. Titles and abstracts of all documents were reviewed for relevance to this topic. The relevant documents were closely examined to find characteristics relevant to this work. If two or more documents talked about the same exoskeleton, either the document detailing the development of the exoskeleton or the first published version was used. The literature review was concluded on 15 October 2019.

\subsection{Data Collection and Presentation}

Through the revision of the extended documentation of this topic, several characteristics that pertained to exoskeletons were found. Thus, there were several ways to present 
the information. Only the main characteristics of design of each exoskeleton were collected as data.

\subsection{Contingency Bias}

Initially, the plan was to only access studies involving exoskeletons in a particular environment; however, those exoskeletons did not portray the full picture of their applications or their general characteristics. Thus, the search was spread to patent databases and companies producing exoskeletons that are currently available for purchase, although exclusive.

\section{Proposed Framework}

Exoskeleton development has come a long way after having evolved for more than one century. However, there are still many upgrades to come as the amount of technology available continues. Throughout the decades, the molds for the modern exoskeletons have been their predecessors, as seen in [11-22]. Aiming with exoskeleton development at the augmentation of human capabilities is a continuous area of opportunity, and in the last decade, it has presented a very steep evolution curve, in contrast to previous decades.

This section will describe the state-of-the-art of the exoskeletons, guided by the timeline presented in Figure 4. The exoskeletons presented in the timeline are the ones selected according to the review methodology, resulting in 75 devices. After the explanation of the timeline, the general categorization model proposal will be presented, using available characteristics in all the exoskeletons analyzed. Finalizing this section are the same exoskeletons presented in the timeline, but this time showing each exoskeleton with its corresponding classification, according to the proposed categorization model.

\subsection{State-of-the-Art Exoskeletons}

The state-of-the-art comprises several exoskeletons made in the last few years. However, due to the large number of exoskeletons, this work reviews only 75 of them, as shown in Figure 4 and using the review methodology proposed previously.

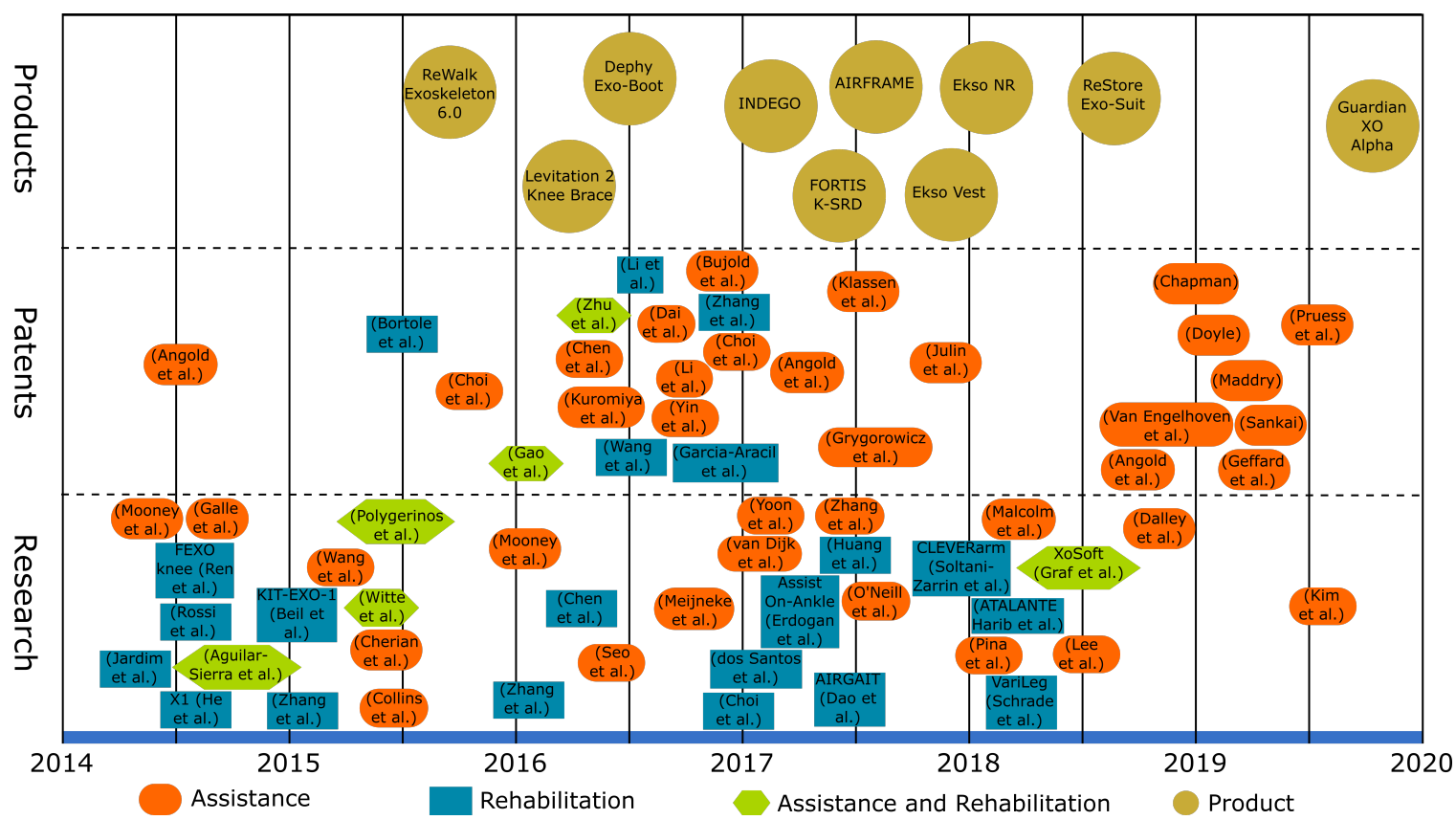

Figure 4. Timeline of the state-of-the-art of 75 different exoskeletons.

Just to clarify, there are far more exoskeletons in existence during the reviewed period; recall the previous scientometric indicators given from 2016 to 2020: there were 5244 works published related to exoskeletons. Hence, the aim of this work is to utilize just a portion of 
the exoskeletons to demonstrate the robustness of the proposed categorization model. This model is just the introduction for the formalization of this research area.

These exoskeletons are represented in a timeline according to the respective dates of the articles/documents/patents in which they were mentioned came out. Moreover, these exoskeletons are separated by the advances that each one has, and whether they are in a research, patent, or product phase. Additionally, each exoskeleton is separated according to whether it has a purpose of assisting, rehabilitating, or both. The top label is for the exoskeletons that are modern day products; some products have an approximate date. Additionally, some of these exoskeletons have previous models, but the latest model currently available in the market is the one presented in the timeline.

As seen in the previous timeline, there are different ways in which an exoskeleton could be classified; one of these is shown in Figure 4. Differentiating exoskeletons by their purposes facilitates the identification of some key parameters, though each exoskeleton may have several unique characteristics. After the review of 75 exoskeletons, a general classification was determined, leading to the diagram proposed in Figure 5.

\subsection{General Categorization}

The general categorization suggests several feasible exoskeleton categories. Such categories have general classes, due to the wide quantity of exoskeletons in existence, and the structure, the body part focused on, the action, the power technology, the purpose, and the application area varying from one to another. Thus, we propose general classes in each classification category, allowing researchers to consider all the exoskeletons in existence, regardless of how specific an exoskeleton could be to a pathology, an application area, or a body part.

For instance, the exoskeleton's purpose could be recovery, performance, or even both. The purpose of each one is not necessarily tied to the specific pathology. For example, a patient who has suffered a stroke could need a recovery exoskeleton; and after the rehabilitation, the same patient could use a performance exoskeleton for the same pathology [23]. Moreover, explaining each exoskeleton using this classification is an optimal way to understand the capabilities of the same exoskeleton, without further explanations of the device's technicalities.

Subsequently, the diagram of Figure 5 will be further explained in detail, for the readers to understand what may or may not be included in each class of each category in order from left to right and top to bottom of the diagram.

Firstly, exoskeletons are not only designed for specific body parts; the exoskeletons may be designed more generally for only one hand, a leg, or even the complete body. Thus, the separation of the classes demonstrates the most common body parts exoskeletons can be built for. The full-body class refers to the exoskeletons made to assist all the limbs, or most of the body. The upper body refers to the exoskeletons made for the upper limbs, and involving the chest, head, back, and/or shoulders. The lower body category refers to the exoskeletons made for the lower limbs: thighs, lower legs, and/or hips. Moreover, there are classes for specific limbs and specific joints. These classes include exoskeletons designed for the knee, ankle, hand, arm, foot, etc. Additionally, there is a special class for any other exoskeleton that is not included in the previous classes.

The second easiest way to differentiate an exoskeleton is by its structure, resulting in the establishment of only two classes, rigid and soft. Rigid exoskeletons are those whose structural components attached to the user's body are made with hard materials. Such materials include metals, plastics, fibers, etc. On the other hand, soft exoskeletons, also called exo-suits, are made with materials that allow free movement of the structural components. Exo-suits are often made with, yet not restricted to, textiles. 


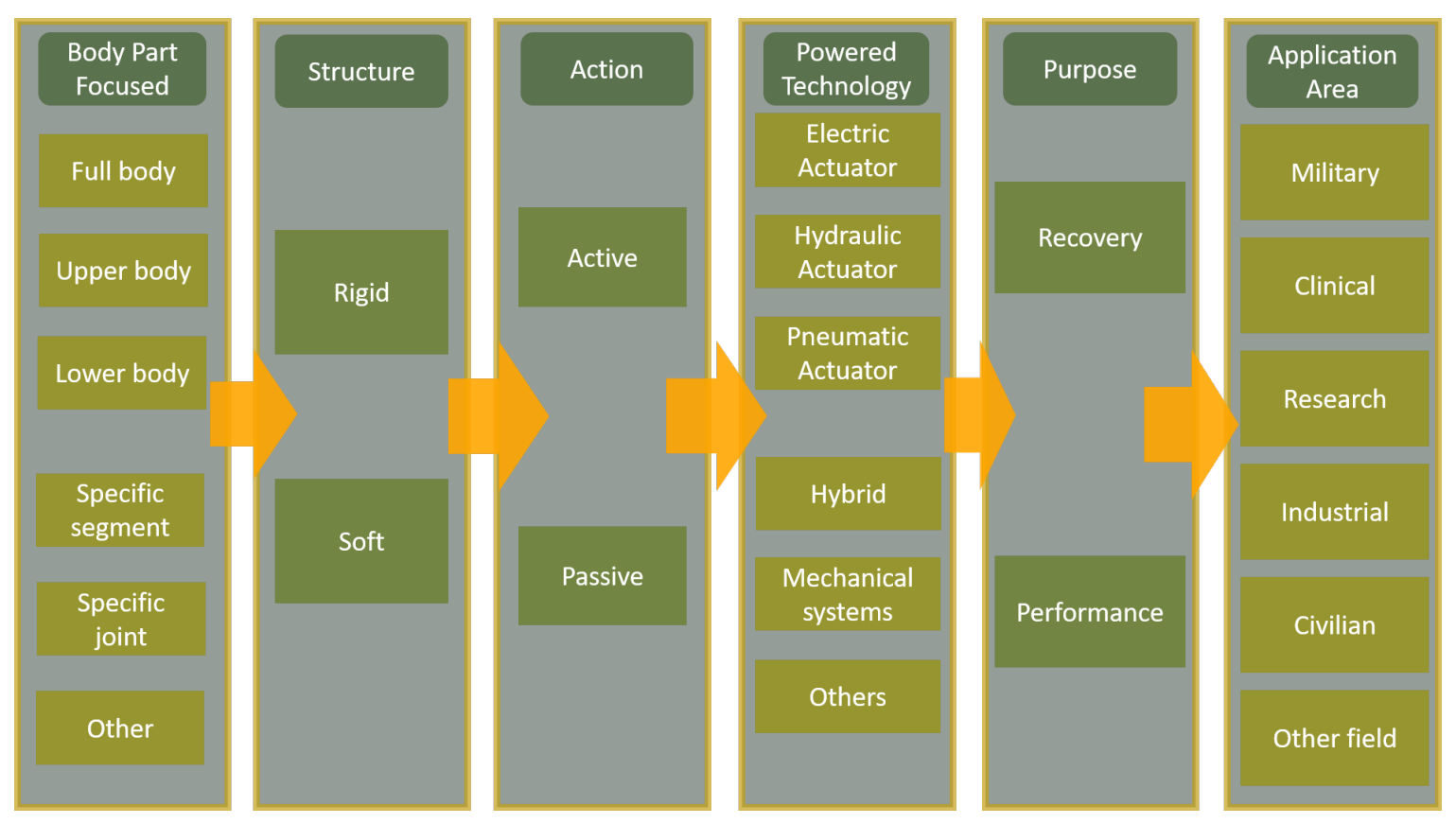

Figure 5. General categorization model proposal for exoskeletons.

Furthermore, the action category describes the type of help the exoskeleton gives the user, dividing exoskeletons into active and passive action. The active class comprises exoskeletons that give "active" aid to the user; in other words, these exoskeletons perform the movements without the need for the user to apply energy. The energy needed to perform the movement is supplied by an external source. On the other hand, the passive class comprises exoskeletons that need the user to perform the movement to work; these exoskeletons do not have power sources. Thus, the user has to perform the movement, and while doing it, the exoskeleton facilitates the movement.

The next category goes hand in hand with the previous one. The powered technologies are separated into four main classes, with one specific class for hybrid and one for any other non-common power technology. The four main classes comprise the electric, hydraulic, and pneumatic actuators as the active action, and the mechanical systems as the passive action. The electric actuators comprise any kind of electric motor that activates the exoskeleton's movements.

Similarly, the hydraulic and pneumatic actuators comprise pistons and soft actuators. Mechanical systems include any system that stores mechanical energy (e.g., springs, dampers) or transmits it (e.g., pulleys, gears). The hybrid class contains all exoskeletons that use a combination of any two or more main classes. The most common hybrids are made with, but are not exclusive to, electrical actuators and mechanical systems. Furthermore, some of the most commonly used hybrids are SEA (series elastic actuators), which are combinations of electric actuators with mechanical systems.

The following category is the exoskeleton's purpose, pertaining to what the exoskeleton will be used for. This category has only two classes: recovery and performance. The recovery exoskeletons are used for rehabilitation; the performance exoskeletons are used for assistance. This paper defined rehabilitation and assistance earlier. Almost all the activities involving exoskeletons that have not been specifically mentioned as seeking to aid with rehabilitation, are activities for performance exoskeletons.

Finally, the last category comprises the application area for which the exoskeleton was made. Each exoskeleton may belong to one or more class. The military class comprises any exoskeleton used for any activity involving an army, navy, airforce, or any other military branch. The medical class comprises the exoskeletons involved in clinical activities, or in general, used in any hospital/clinic. Additionally, the recovery exoskeletons are normally classified in the medical class. Furthermore, the research class comprises the exoskeletons 
that are nowadays in their research development phase. The industrial class, as its name suggests, encompasses those exoskeletons made specifically for industrial activities. These exoskeletons are characterized for being used by people without any pathology seeking the avoidance of long-term physical damages. This description also applies to military exoskeletons. The civilian class is for the recovery or performance exoskeletons made for people to use in their homes or public spaces, aiding in tasks that people cannot perform as easily alone. Finally, there is a class for exoskeletons in which the applications do not fit into any of the previous classes.

These are the definitions for each class presented in the categorization model in Figure 5. Additionally, this review proposes the classification of all the exoskeletons presented in the timeline of Figure 4. Following the previous classification proposed in Figure 5, each one of the exoskeletons mentioned may be found in Tables 1 and 2. All the exoskeletons are classified according to the given descriptions with the information found from each article/document/patent.

Table 1. Classification of the state-of-the-art of exoskeletons (Part I).

\begin{tabular}{|c|c|c|c|c|c|c|}
\hline Author & $\begin{array}{l}\text { Body Part } \\
\text { Focused }\end{array}$ & Structure & Action & $\begin{array}{l}\text { Powered } \\
\text { Technology }\end{array}$ & Purpose & $\begin{array}{l}\text { Application } \\
\text { Area }\end{array}$ \\
\hline X1 (He et al., 2014) [24] & Lower body & Rigid & Active & $\begin{array}{c}\text { Hybrid } \\
\text { (Electrical/Mechanical) }\end{array}$ & Recovery & Research \\
\hline FEXO knee (Ren et al., 2014) [25] & Knee & Rigid & Active & $\begin{array}{c}\text { Hybrid } \\
\text { (Electrical/Mechanical) }\end{array}$ & Recovery & Research \\
\hline (Aguilar-Sierra et al., 2014) [26] & Lower body & Rigid & Active & Hybrid (Electrical/Mechanical) & Both & Research \\
\hline (Jardim et al., 2014) [27] & Ankle & Rigid & Active & Hybrid (Electrical/Mechanical) & Recovery & Research \\
\hline WAKE-up (Rossi et al., 2014) [28] & Lower body & Rigid & Active & Hybrid (Electrical/Mechanical) & Recovery & Research \\
\hline (Angold et al., 2014) [29] & Lower body & Rigid & Active & Hybrid (Electrical/Mechanical) & Performance & Not classified \\
\hline (Galle et al., 2014) [30] & Lower leg & Rigid & Active & Pneumatic actuator & Performance & Research \\
\hline (Mooney et al., 2014) [31] & Lower Leg & Rigid & Active & Hybrid (Electrical/Mechanical) & Performance & Research \\
\hline (Collins et al., 2015) [32] & Lower Leg & Rigid & Passive & Mechanical & Performance & Research \\
\hline KIT-EXO-1 (Beil et al., 2015) [33] & Lower body & Rigid & Active & Hybrid (Electrical/Mechanical) & Recovery & Research \\
\hline (Wang et al., 2015) [34] & Lower body & Rigid & Active & $\begin{array}{c}\text { Hybrid } \\
\text { (Electrical/Mechanical) }\end{array}$ & Performance & Research \\
\hline (Zhang et al., 2015) [35] & Ankle & Rigid & Active & Hybrid (Electrical/Mechanical) & Recovery & Research \\
\hline (Cherian et al., 2015) [36] & Knee & Soft & Passive & Mechanical & Performance & Civilian \\
\hline (Polygerinos et al., 2015) [37] & Hand & Soft & Active & Hydraulic Actuator & Both & Civilian/Clinical \\
\hline (Witte et al., 2015) [38] & Ankle & Rigid & Active & Hybrid (Electrical/Mechanical) & Both & Research \\
\hline (Choi et al., 2015) [39] & Lower body & Rigid & Active & $\begin{array}{c}\text { Hybrid } \\
\text { (Electrical/Mechanical) }\end{array}$ & Performance & Not classified \\
\hline (Bortole et al., 2015) [40] & Lower body & Rigid & Active & Electric Actuators & Recovery & Clinical \\
\hline (Zhu et al., 2016) [41] & Upper body & Rigid & Active & $\begin{array}{c}\text { Hybrid } \\
\text { (Electrical/Mechanical) }\end{array}$ & Both & Clinical/Industrial \\
\hline (Chen et al., 2016) [42] & Lower body & Rigid & Active & Hybrid (Electrical/Mechanical) & Recovery & Research \\
\hline (Zhang et al., 2016) [43] & Lower body & Rigid & Active & $\begin{array}{c}\text { Hybrid } \\
\text { (Electrical/Mechanical) }\end{array}$ & Recovery & Research \\
\hline (Wang et al., 2016) [44] & Hand & Rigid & Active & Hybrid (Electrical/Mechanical) & Recovery & Not classified \\
\hline (Bujold et al., 2016) [45] & Full body & Rigid & Passive & Mechanical & Performance & Civilian \\
\hline (Kuromiya et al., 2016) [46] & Lumbar region & Rigid & Active & Electric Actuator & Performance & Not classified \\
\hline (Yin et al., 2016) [47] & Upper body & Rigid & Active & Hybrid (Electrical/Mechanical) & Performance & Industrial \\
\hline $\begin{array}{l}\text { (Mooney et al., } \\
\text { 2016) [48] }\end{array}$ & Lower Leg & Rigid & Active & Electric Actuator & Performance & Research \\
\hline
\end{tabular}


Table 1. Cont.

\begin{tabular}{|c|c|c|c|c|c|c|}
\hline Author & $\begin{array}{l}\text { Body Part } \\
\text { Focused }\end{array}$ & Structure & Action & $\begin{array}{l}\text { Powered } \\
\text { Technology }\end{array}$ & Purpose & $\begin{array}{l}\text { Application } \\
\text { Area }\end{array}$ \\
\hline $\begin{array}{l}\text { (Gao et al., } \\
\text { 2016) [49] }\end{array}$ & Arm & Rigid & Active & Hybrid (Electrical/Mechanical) & Both & Not classified \\
\hline $\begin{array}{l}\text { (Li et al., } \\
\text { 2016) [50] }\end{array}$ & Lower body & Rigid & Active & Electric Actuator & Performance & Not classified \\
\hline $\begin{array}{l}\text { (Li et al., } \\
\text { 2016) [51] }\end{array}$ & Upper body & Rigid & Active & Hybrid (Electrical/Mechanical) & Recovery & Clinical \\
\hline $\begin{array}{l}\text { (Dai et al., } \\
\text { 2016) [52] }\end{array}$ & Ankle & Rigid & Active & Hybrid (Electrical/Mechanical) & Performance & Industrial \\
\hline $\begin{array}{l}\text { (Chen et al., } \\
\text { 2016) [53] }\end{array}$ & Lower body & Rigid & Active & Hybrid (Hydraulic/Mechanical) & Performance & Not classified \\
\hline $\begin{array}{l}\text { (Seo et al., } \\
\text { 2016) [54] }\end{array}$ & Hip & Rigid & Active & Electric Actuator & Performance & Research/Civilian \\
\hline $\begin{array}{c}\text { (Garcia-Aracil et al., } \\
\text { 2016) [55] }\end{array}$ & Hand & Rigid & Active & Pneumatic Actuator & Recovery & Clinical \\
\hline $\begin{array}{l}\text { (Choi et al., } \\
\text { 2016) [56] }\end{array}$ & Lower body & Rigid & Active & Hybrid (Electrical/Mechanical) & Performance & Not classified \\
\hline (Meijneke et al., 2017) [57] & Lower body & Rigid & Active & Electric Actuator & Performance & Civilian/Research \\
\hline $\begin{array}{l}\text { (van Dijk et al., } \\
\text { 2017) [7] }\end{array}$ & Lower Leg & Rigid & Passive & Hybrid (Electrical/Mechanical) & Performance & Research \\
\hline (O'Neill et al., 2017) [58] & Shoulder & Soft & Active & Pneumatic Actuator & Performance & Civilian \\
\hline (Huang et al., 2017) [59] & Lower body & Rigid & Active & $\begin{array}{c}\text { Hybrid } \\
\text { (Electrical/Mechanical) }\end{array}$ & Recovery & Research \\
\hline
\end{tabular}

Table 2. Classification of the state-of-the-art of exoskeletons (Part II).

\begin{tabular}{|c|c|c|c|c|c|c|}
\hline Author & $\begin{array}{l}\text { Body Part } \\
\text { Focused }\end{array}$ & Structure & Action & $\begin{array}{l}\text { Powered } \\
\text { Technology }\end{array}$ & Purpose & $\begin{array}{l}\text { Application } \\
\text { Area }\end{array}$ \\
\hline (Angold et al., 2017) [60] & Lower body & Rigid & Passive & Mechanical & Performance & Not classified \\
\hline (Choi et al., 2017) [61] & Knee & Rigid & Active & Hybrid (Electrical/Mechanical) & Recovery & Research \\
\hline (Zhang et al., 2017) [62] & Hand & Soft & Active & Pneumatic Actuator & Recovery & Not classified \\
\hline $\begin{array}{c}\text { AIRGAIT } \\
\text { (Dao et al., 2017) [63] }\end{array}$ & Lower body & Rigid & Active & Pneumatic Actuator & Recovery & Research \\
\hline (Yoon et al., 2017) [64] & Lower body & Rigid & Active & Not classified & Performance & Not classified \\
\hline $\begin{array}{l}\text { (dos Santos et al., } \\
\text { 2017) [65] }\end{array}$ & Knee & Rigid & Active & Hybrid (Electrical/Mechanical) & Recovery & Research \\
\hline $\begin{array}{c}\text { Assist On-Ankle } \\
\text { (Erdogan et al., 2017) [8] }\end{array}$ & Ankle & Rigid & Active & Hybrid (Electrical/Mechanical) & Recovery & Research \\
\hline (Julin et al., 2017) [66] & Lower body & Rigid & Active & Hybrid (Electrical/Mechanical) & Performance & Civilian/Military \\
\hline $\begin{array}{c}\text { (Grygorowicz et al., } \\
\text { 2017) [67] }\end{array}$ & Lower body & Rigid & Active & Hydraulic Actuator & Performance & Military \\
\hline $\begin{array}{l}\text { CLEVERarm (Soltani-Zarrin et al., } \\
\text { 2017) [68] }\end{array}$ & Upper body & Rigid & Active & Electric Actuator & Recovery & Clinical \\
\hline (Zhang et al., 2017) [69] & Lower leg & Rigid & Active & Hybrid (Electrical/Mechanical) & Performance & Research \\
\hline
\end{tabular}


Table 2. Cont.

\begin{tabular}{|c|c|c|c|c|c|c|}
\hline Author & $\begin{array}{l}\text { Body Part } \\
\text { Focused }\end{array}$ & Structure & Action & $\begin{array}{l}\text { Powered } \\
\text { Technology }\end{array}$ & Purpose & $\begin{array}{l}\text { Application } \\
\text { Area }\end{array}$ \\
\hline (Klassen, 2017) [70] & Lower body & Rigid & Active & Electric Actuator & Performance & Civilian \\
\hline (Pina et al., 2018) [71] & Lower body & Rigid & Active & Electric Actuator & Performance & Civilian \\
\hline (Malcolm et al., 2018) [6] & Lower body & Rigid & Active & $\begin{array}{c}\text { Hybrid } \\
\text { (Pneumatic/Electrical) }\end{array}$ & Performance & Clinical/Research \\
\hline $\begin{array}{c}\text { VariLeg } \\
\text { (Schrade et al., 2018) [72] }\end{array}$ & Lower body & Rigid & Active & Hybrid(Electrical/Mechanical) & Recovery & Research \\
\hline $\begin{array}{c}\text { (Van Engelhoven et al., } \\
\text { 2018) [73] }\end{array}$ & Upper body & Rigid & Passive & Mechanical & Performance & Not classified \\
\hline (Dalley et al., 2018) [74] & Lower body & Rigid & Active & Electric Actuator & Performance & Civilian/Research \\
\hline (Angold et al., 2018) [75] & Upper body & Rigid & Passive & Mechanical & Performance & Not classified \\
\hline $\begin{array}{c}\text { XoSoft } \\
\text { (Graf et al., 2018) [76] }\end{array}$ & Lower body & Soft & Active & $\begin{array}{c}\text { Hybrid } \\
\text { (Electrical/Mechanical) }\end{array}$ & Both & Research \\
\hline $\begin{array}{c}\text { ATALANTE } \\
\text { (Harib et al., 2018) [77] }\end{array}$ & Lower body & Rigid & Active & Electric Actuator & Recovery & Clinical \\
\hline (Lee et al., 2018) [78] & Lower body & Soft & Active & $\begin{array}{c}\text { Hybrid } \\
\text { (Electrical/Mechanical) }\end{array}$ & Performance & Research \\
\hline (Chapman, 2019) [79] & Lower body & Rigid & Passive & Mechanical & Performance & Military \\
\hline (Geffard et al., 2019) [80] & Lower body & Rigid & Active & Electric Actuator & Performance & Research/Civilian \\
\hline (Maddry, 2019) [81] & Full body & Rigid & Active & Pneumatic Actuator & Performance & Not classified \\
\hline (Sankai, 2019) [82] & Upper body & Rigid & Active & Mechanical & Performance & Industrial \\
\hline $\begin{array}{l}\text { (Kim et al., } \\
\text { 2019) [83] }\end{array}$ & Lower body & Soft & Active & $\begin{array}{c}\text { Hybrid } \\
\text { (Electrical/Mechanical) }\end{array}$ & Performance & Civilian \\
\hline $\begin{array}{l}\text { (Pruess et al., } \\
\text { 2019) [84] }\end{array}$ & Other & Rigid & Active & Hybrid & Performance & Industrial \\
\hline (Doyle, 2019) [85] & Arm & Rigid & Passive & Mechanical & Performance & Industrial \\
\hline $\begin{array}{c}\text { ReWalk } \\
\text { Exoskeleton } 6.0[86,87]\end{array}$ & Lower body & Rigid & Active & Electric Actuator & Both & Civilian/Clinical \\
\hline Dephy Boot [88] & Lower Leg & Rigid & Active & Electric Actuator & Performance & Military/Civilian/Research \\
\hline INDEGO (Farris et al., 2017) [89-91] & Lower body & Rigid & Active & Electric Actuator & Both & Civilian/Clinical \\
\hline AIRFRAME (Doyle, 2017) $[92,93]$ & Shoulders & Rigid & Passive & Mechanical & Performance & Industrial \\
\hline FORTIS K-SRD [94] & Lower body & Rigid & Active & Electric Actuator & Performance & Military/Industrial \\
\hline Ekso Vest $[95,96]$ & Upper body & Rigid & Passive & Mechanical & Performance & Industrial \\
\hline Ekso NR [97] & Lower body & Rigid & Active & Electric Actuator & Recovery & Clinical \\
\hline $\begin{array}{c}\text { Levitation } 2 \\
\text { Knee Brace }[98,99]\end{array}$ & Knee & Rigid & Passive & Mechanical & Performance & Civilian \\
\hline ReStore Exo-Suit [100] & Ankle & Soft & Active & $\begin{array}{c}\text { Hybrid } \\
\text { (Electrical/Mechanical) }\end{array}$ & Recovery & Clinical \\
\hline Guardian XO [101,102] & Full body & Rigid & Active & Hybrid(Electrical/Mechanical) & Performance & Industrial/Military \\
\hline
\end{tabular}

\section{Analysis and Discussion}

Exoskeletons are used to target many pathologies, traumatisms, degenerations, and malformations; thus, they have a wide range of models. From full-body to a specific joint, exoskeletons can aid people with different needs. There are certain categories that are needed to emphasize for these designs. Incidentally, we must not forget that this is a review of the general state-of-the-art of exoskeletons, adding a classification for further use in the exoskeleton topic. There are other reviews that present data and information on specific categories of this classification [23,103-109].

There are multiple different reviews pertaining to exoskeletons with different focuses; for instance, Pawel Maciejasz reviewed robotic devices for upper limb rehabilitation, which were not limited to upper limb exoskeletons. Such reviews provide a helpful starting 
point for the readers to inform themselves on which devices focus on the upper limbs and their recovery [104]. Soumya Manna reviewed actuation systems for upper limb exoskeletons [106], and Ruwan Gopura presented the developments in hardware for the active upper limb exoskeletons [107].

Presently, there are also many reviews that focus on the lower limbs; for example, Larry Miller reviewed exoskeletons assisting with walking in patients with spinal cord injuries [105]. Pilwon Heo presented a review of hand exoskeleton technologies [103], Aaron Young presented one on lower limb exoskeletons in general [109], and SánchezVillamañan detailed many lower limb exoskeletons [23].

Nevertheless, reviews may focus on aspects of exoskeletons other than the body type where they are meant to be used. One example is Voilqué's review, which focused on exoskeletons applied industrially [108]. Such reviews denote that exoskeletons may be categorized following the multiple classifications mentioned in Figure 5. Thus, a general state-of-the-art categorization is imperative. According to the state-of-the-art, shown in Tables 1 and 2, exoskeletons may be organized into multiple categories demonstrating tendencies in their developments. Following the same order as the proposed categorization, the analysis of each category is presented below.

\subsection{Body Part Focused Category}

This category is intended to represent every part of the body on which an exoskeleton may be used. It generally refers to which part of the body the exoskeleton is designed to aid. Exoskeletons are not designed only for the full, upper, or lower body. They may be designed to fit on to a specific body part.

The first class, in order of appearance in Figure 6, is the full body class, which is the smallest class of exoskeletons containing only $4 \%$ of all the exoskeletons analyzed. This can be explained by the fact that few users demand the use of a full body exoskeleton. Despite the fact that many full body exoskeletons have been developed in the past, the current tendency is the decrease in their invention and demand. For this reason, full body exoskeletons denote a risky area of opportunity, which although full of potential, are quite risky due to their low demand.



Figure 6. Chart of the classification of exoskeletons by the body parts on which the exoskeletons are focused.

The lower body class encompasses more than half of the exoskeletons reviewed, with a $56 \%$ frequency. This is because most exoskeletons are designed to help a user with mobility issues. The most frequent mobility issues are associated with problems in the lower half of the body. Thus, there is a high tendency to design a lower-body exoskeleton. In contrast, the upper body class only encompasses $15 \%$ of the exoskeletons reviewed. This denotes a lower frequency of mobility issues relating to the upper body. Nevertheless, upper body exoskeletons are used in many application areas, and are imperative in the exoskeleton field. 
Additionally, specific limb exoskeletons account for only $8 \%$ of all exoskeletons analyzed, and specific joint exoskeletons 16\%, representing a minority of the exoskeletons designed. This demonstrates that only about a quarter of all the exoskeletons are designed for a specific body part. The specific joint category is generally any joint in which an exoskeleton can be focused, for instance, the knee, ankle, or elbow, among others. Finally, another category was included to represent any exoskeleton reviews that did not fit into any of the previously mentioned categories. This is uncommon ( $1 \%$ of all exoskeletons reviewed) but possible, hence the annexation of the class.

\subsection{Structure Category}

This category discusses the structure classification of the exoskeletons, rigid and soft. Of the 75 exoskeletons discussed, 67 were designed with a rigid structure and only 8 with a soft structure. The comparison is abysmal- $89 \%$ of the exoskeletons being rigid and $11 \%$ being soft. Each structure class has its advantages and disadvantages. The rigid structure exoskeletons are made for tougher conditions and environments, being more robust than soft exoskeletons; commonly these exoskeletons carry some or all the weight of the user. Soft exoskeletons (exo-suits) are more common in everyday applications, where the suit does not experience high amounts of stress. There are made to fit the wearer, and represent a small additional weight. In contrast, rigid structure exoskeletons add more weight to the wearer, and depending on the design and use, the distribution of the weight may vary. This distribution allows the suit to handle extra weight carried in the back of the user, such as a backpack or military/industrial equipment $[29,94,96]$.

\subsection{Action Category}

The action category portrays the action classification of the exoskeletons in Figure 7, and is divided into two groups: passive and active. The review showed that there is a greater tendency to design active exoskeletons with a $83 \%$, in contrast to $17 \%$ of passive exoskeletons.

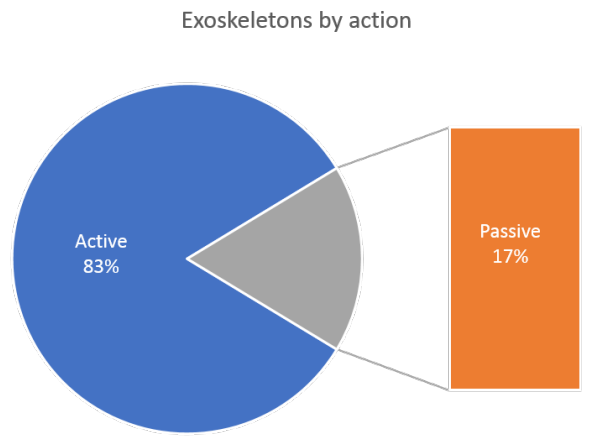

Figure 7. This chart portrays the classification of exoskeletons by the kinds of action given to the user.

This is mainly due to the higher level of assistance that the active exoskeletons may provide in comparison to the passive ones. Passive exoskeletons are mainly designed for people who have diminished amounts of strength, but may still perform the activities needed. People who desire to augment their performance, even ever so slightly, may prefer this option that also manages to reduce around $7.2 \pm 2.6 \%$ of metabolic energy [32] in certain cases.

In contrast, the active exoskeletons, in general, have more robust activities; they aid or even execute the needed movements instead of the user. Some authors use the term quasi-passive, which is not a category used in this paper. Quasi-passive exoskeletons reduce the work of the actuators or the wearer by using mechanical systems [21]; this work describes this type of action as active, due to the use of actuators. Nevertheless, exoskeletons can be also classified as quasi-passive, depending on the author's perspective. 


\subsection{Powered Technology Category}

Powered technologies are generally divided according to the principles behind their functionality. The principles behind pneumatic, hydraulic, and electrical actuators are different, and the mechanical systems were previously described. Each kind of actuator has its own advantages, so in practice, a combination is commonly used. In Figure 8 is presented a chart with the classification of technologies used to power exoskeletons.

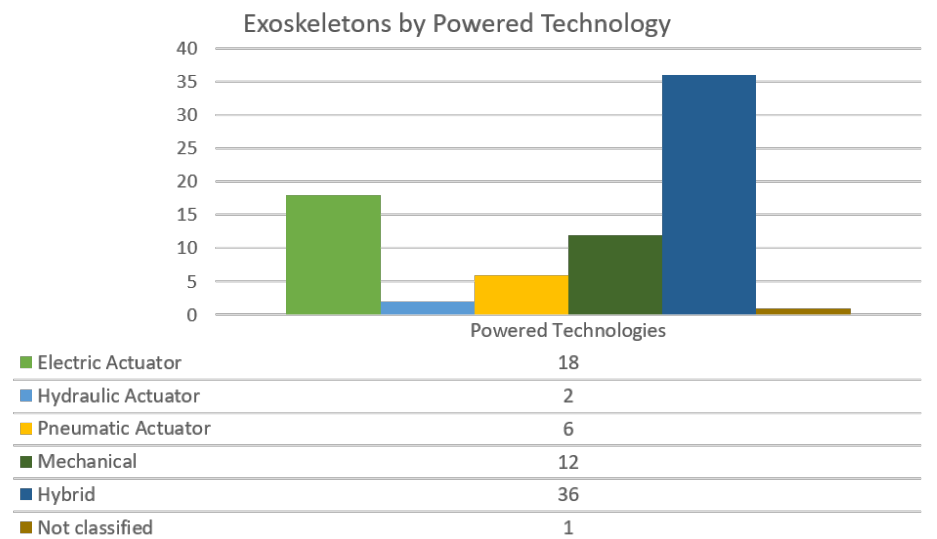

Figure 8. This plot portrays the classification of exoskeletons by the technology used to power the device.

Some of the most commonly used power sources are hybrid ones, with a percentage of $48 \%$, representing almost half of all the exoskeletons reviewed. The most common hybrids have some combination of electrical actuators and mechanical systems, using the mechanical systems to transmit energy or movement to other sections of the exoskeleton; however, there are many other types of hybrid combinations.

Electric actuators are the second most used for exoskeletons-24\% of all the exoskeletons analyzed in this review. These actuators are often used when the exoskeleton has to provide a more controlled movement, due to the fact that these actuators have high precision. Hydraulic and pneumatic actuators follow, being only 3\% and $8 \%$ respectively. These actuators need a fixed source of a fluid or compressed air, hence the low percentage of exoskeletons using them.

On the other hand, mechanical exoskeletons are the third most used, encompassing $16 \%$ of the exoskeletons reviewed. Mechanical exoskeletons are also passive exoskeletons, due to the lack of a source power. Finally, $1 \%$ of the exoskeletons analyzed did not belong to any of the other categories as the design only included a space for an actuator without specifying which type [64].

\subsection{Purpose Category}

One of the most important categories for the exoskeletons is purpose. The purpose helps set a path for an exoskeleton. Additionally, it may be the first decision to to be made in the process of designing an exoskeleton. The purpose of an exoskeleton may fit into either of two categories, performance or recovery; however, certain exoskeletons are robust enough to have both purposes. Proportions of exoskeletons according to purpose are presented in Figure 9. 




Figure 9. This chart portrays the classification of exoskeletons according to their purposes.

More than half of all the exoskeletons reviewed were used for performance, specifically $59 \%$. On the other hand, 31\% of all the exoskeletons were used for recovery, and the exoskeletons having both purposes only encompassed $11 \%$ of the exoskeletons reviewed, as seen in Figure 9. Recovery exoskeletons are focused on specific pathologies, making them harder to produce than performance exoskeletons that have some more general use. Additionally, recovery exoskeletons cannot be used in settings outside of the ones they were designed for, making them generally less practical than performance problems.

\subsection{Application Area Category}

As previously mentioned, exoskeletons may be classified according to the application they were designed for. Some categories following this classification are shown in Figure 10. Many of the previous exoskeletons fit in the research category, but in this case, research is considered an extra step in product development. From the reviewed exoskeletons, 25 are still in the research phase (33\%), 7 are made for civilians ( $9 \%), 7$ for clinical use $(9 \%), 7$ for industrial use ( $9 \%), 2$ for military use (3\%), 12 for multiple areas $(17 \%)$, and 15 are not classified (19\%), due to the lack of information on their formal usage in real-life applications.



Figure 10. This chart portrays the classification of the exoskeletons by the field(s) of use.

\subsection{Exoskeleton Research Opportunities}

Figures 6-10 shows clear tendencies when designing an exoskeleton. For instance, one of the most balanced categorization methods is that of exoskeleton applications, which has several classes that have the same number of exoskeletons. In contrast, the body part focused category has a clear bias towards lower body exoskeletons, due to the low percentages of the rest of the classes. 
According to this review, the researchers can identify with the graphs and statistics the popular exoskeleton topics nowadays, demonstrating that some areas of the exoskeletons have been developed more than others.

\subsection{Control Strategies in Exoskeletons}

A topic that is not debated in this review is the control strategies used in exoskeletons. The General Categorization model of the exoskeletons is intended to be used when an author wants to classify an exoskeleton. However, there are more areas that can be discussed when boarding exoskeletons, leading to a far more complex and larger model.

One of the reasons that the control strategies of the exoskeletons are not included in the categorization is the wide variety of control techniques. Moreover, some exoskeletons do not implement any particular control. Out of the 75 exoskeletons discussed, only the research exoskeletons could be analyzed by their control techniques, resulting in the analysis of only 37 exoskeletons, almost half of all the exoskeletons reviewed and these ones are represented in Figure 11.

Furthermore, from these 37 exoskeletons, 2 could not be classified, because there was a lack of information regarding the control specifications, they were placed under the "Not specified" label. Nevertheless, the analysis was made, separating exoskeletons in the control loop and the control technique used.

Regarding the control loop used in exoskeletons, and presented in Figure 11, almost all exoskeletons have a close control loop with $86.5 \%$, due to the fact that all of these exoskeletons have a different type of control technique. On the other hand, only $8.1 \%$ have an open control loop, meaning that these exoskeletons are not controlled while the user is wearing it. Additionally, and as previously mentioned, the graph shows $5.4 \%$ as "Not specified".

Moreover, the exoskeletons with a close control loop have different types of control techniques. Presented in Figure 12 is a representation of all the control techniques used, including 11 different techniques, plus the exoskeletons that do not have a control mechanism and the exoskeletons that are not specified.

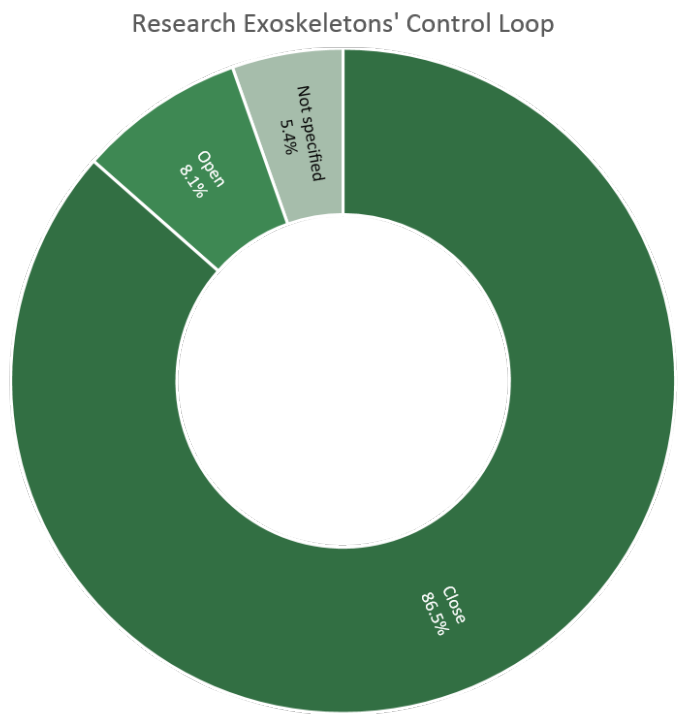

Figure 11. This chart portrays the control loop of the exoskeletons in the research phase.

\subsection{Control Techniques}

There are different ways to control a device, also an exoskeleton. The actuators and mechanisms need to be controlled to provide the expected augmentation. The control method technique used in each exoskeleton may lead to a higher or lower efficiency, depending also on the activity in which the exoskeleton is used. The mention of control techniques is important for any person who is interested on exoskeletons, because it 
provides the control techniques used until now for the development of other exoskeletons. The control techniques found in the previous exoskeletons are represented in Figure 12.

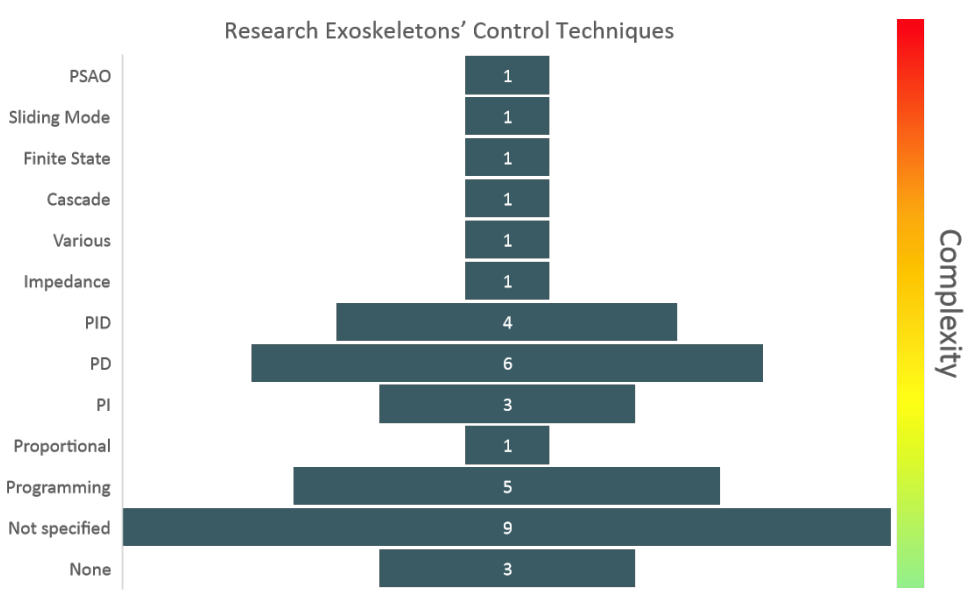

Figure 12. This figure portrays the control techniques of the exoskeletons in the research phase and distributes the techniques by the complexity.

From the 11 different control techniques mentioned, some are very common in the field of control, such as the PID, PD or PI controllers. Others that are less common, such as Impedance [34] or Cascade [8]. Certain techniques are unique to their respective authors, like the PSAO [54]. The previous figure (Figure 12) portrays these techniques graphically from least to highest level of complexity.

\subsection{Actuators and Algorithms}

As previously mentioned, the objective of this review was to present the state-ofthe-art of the exoskeletons (Figure 4), provide a general categorization (Figure 5) and to classify each exoskeleton (Tables 1 and 2). The annexation of a more detailed description of actuators and algorithms is not a part of the scope of this review, as their lack of both.

As previously mentioned, from 2010 to 2020, there have been 8391 articles indexed to Scopus $\left({ }^{\circledR}\right)$ related to exoskeletons. Some of these articles are reviews of different technologies and techniques used in exoskeleton development or are about exoskeletons in general. The average number of citations of these articles is 9.173 cites per article.

The most cited exoskeletons are mentioned in the following section along with a brief description of each one.

\subsection{Mooney's Exoskeleton Model}

The Mooney's Exoskeleton model is described as a fully autonomous leg exoskeleton. However, it may also be described as a rigid lower leg performance exoskeleton, with an active action given by Electrical actuators and Mechanical systems. This exoskeleton could reduce the metabolic burden of walking during load carriage. Such reduction increases in magnitude with the weight of the load. Mainly, this exoskeleton allows the carrying of greater loads at the same nominal metabolic cost as when the user is not carrying loads [31].

\subsection{Collins' Exoskeleton Model}

The Collins' Exoskeleton is described as a lightweight exoskeleton that reduces human metabolic energy consumption. This exoskeleton, can be more generally described as, a rigid lower leg performance exoskeleton, similar to the previous model. Nevertheless, this exoskeleton has a passive action, powered only by mechanical systems, specifically a spring. The Collins' model and Mooney's model are similar exoskeletons, made for reducing metabolic consumption, their main difference is their powering source [32]. 


\subsection{Polygerinos' Exoskeleton Model}

The Polygerinos' Exoskeleton model has a unique design, being a soft, hydraulicpowered hand exoskeleton, that has the purpose of assisting and rehabilitating. It may be further described as a portable, assistive, soft robotic glove designed to augment hand recovery. The use of soft actuators allows for more freedom of hand movement, providing more control and stability than a rigid structure that would press against the hand. This exoskeleton is described to have an innovative design, being powered by soft hydraulic actuators, providing the user freedom and independence [37].

\subsection{H2 Exoskeleton}

The H2 Exoskeleton (Figure 13) is described as a lower limb exoskeleton designed for the recovery of stroke patients; it is lightweight and battery-powered [40]. Additionally, this exoskeleton has only electric actuators propelling the movement of the user, thus, having an active action.

Furthermore, the $\mathrm{H} 2$ is a lower limb exoskeleton that has 6 degrees of freedom, contrasting to the previous models discussed.

The classification of exoskeletons by pathology was not suggested as such category would be very extensive. Secondly, exoskeletons are not designed only for health conditions, but also to avoid such health problems and facilitate physical tasks.

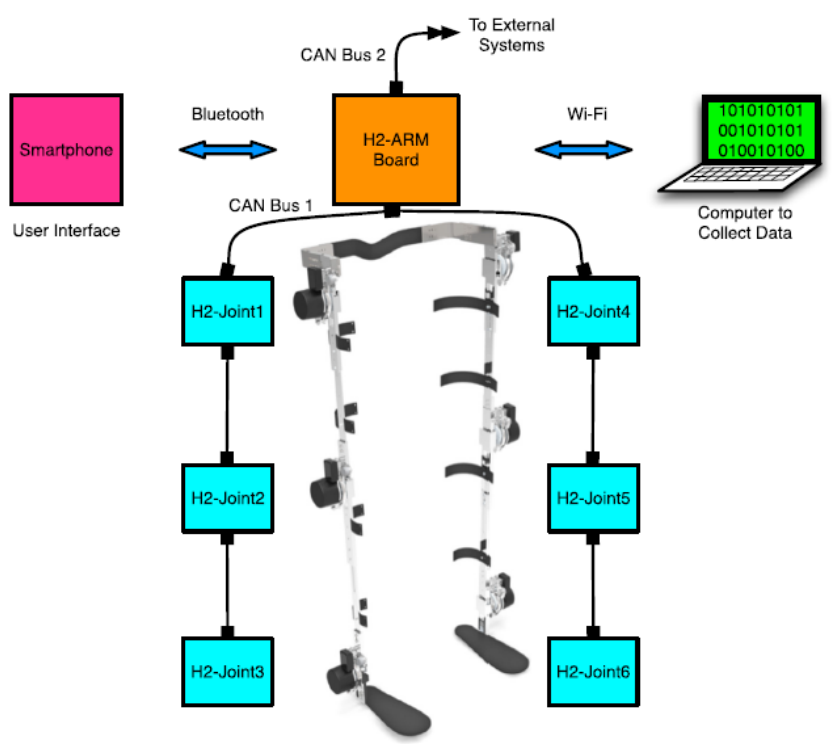

Figure 13. Control architecture of the H2 Exoskeleton [40].

\subsection{Scientometric Indicators}

There are some interesting and important indicators to highlight from the research of exoskeletons. The data used for these indicators can be found in the supplementary materials. For instance, the top 10 authors with the most publications of articles related to exoskeletons are presented in Figure 14.

While, the top 10 institutions with the most publications including the term "exoskeletons" in their name, abstract, or keywords, between 2010-2020 are shown in Figure 15 




Figure 14. Graph of the top 10 authors by number of publications referring to exoskeletons between 2010 and 2020.

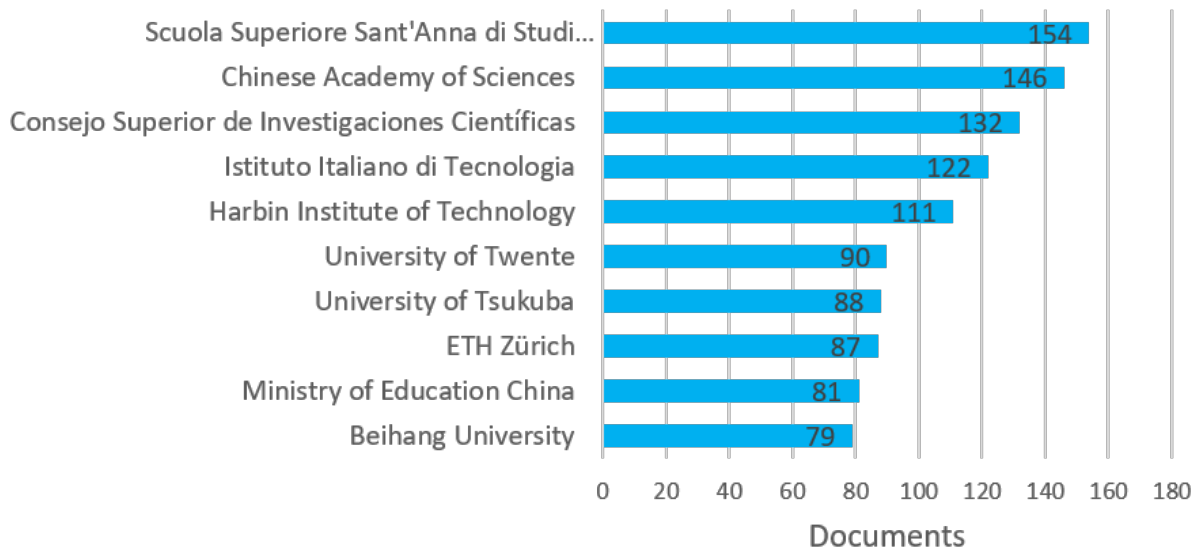

Figure 15. Graph of the top 10 institutions by number of publications referring to exoskeletons between 2010 and 2020 .

\subsection{Findings}

This work presents a large review of the state-of-the-art of all exoskeletons. The most relevant contribution of this work is the general categorization model of exoskeletons (shown in Figure 5), providing a new way to classify any exoskeleton and formalize the topic for its further use in society. The categorization, previously presented, is important because it gives an order and organization to the exoskeletons, which is currently lacking in the field.

Understanding the general picture of the whole exoskeleton field was difficult and time consuming before the proposal of the categorization system hereby. For example, as research on lower limb performance exoskeletons is currently so extensive, researchers new to the field could have a tendency to focus their efforts on the sole development of this type of exoskeleton. This work provides the past and present of exoskeletons, while simultaneously establishing the basis for future investigation in this field.

Moreover, this categorization encompasses any exoskeleton design made up until present day, dividing them into six categories. There are a total of 1728 different designs resulting from all the possible combinations of classes previously proposed, including impossible ones, as seen in Table 3 . These six categories precisely describe any exoskeleton, which is one of the aims of this article, to pioneer categorization of exoskeletons so that any 
researcher involved in this area may use it to describe its work and give recommendations for further exoskeleton design.

Furthermore, the following table (Table 3), shows a comparative table on recommendations for future work on exoskeletons, in case they are new to the field and are still not sure what type of exoskeleton to pursue. Additionally, the table gives a recommendation for each comparative, divided into highly recommended, moderately recommended, not recommended, and not possible.

Finally, as previously mentioned, this work sets a precedent in the field, and intends to be used as a reference in the future.

Table 3. This table is comparing different classes of the exoskeletons and grading them with a recommendation level

\begin{tabular}{c|c|c|c|c|c|c} 
Exoskeletons & Rigid & Soft & Active & Passive & Performance & Recovery \\
Full body & $(++)$ & $(+)$ & $(++)$ & $(-)$ & $(++)$ & $(-)$ \\
Upper body & $(+)$ & $(++)$ & $(+)$ & $(++)$ & $(++)$ & $(+)$ \\
Lower Body & $(++)$ & $(++)$ & $(++)$ & $(++)$ & $(++)$ & $(++)$ \\
Specific Segment & $(+)$ & $(++)$ & $(+)$ & $(++)$ & $(++)$ & $(+)$ \\
Specific Joint & $(++)$ & $(-)$ & $(++)$ & $(-)$ & $(+)$ & $(++)$ \\
Electrical & $(++)$ & $(-)$ & $(++)$ & $(-)$ & $(++)$ & $(++)$ \\
Hydraulic & $(++)$ & $(-)$ & $(++)$ & $(-)$ & $(++)$ & $(-)$ \\
Pneumatic & $(++)$ & $(-)$ & $(++)$ & $(-)$ & $(++)$ & $(++)$ \\
Mechanical & $(-)$ & $(++)$ & $(-)$ & $(++)$ & $(++)$ & $(-)$ \\
Hybrid & $(++)$ & $(+)$ & $(++)$ & $(-)$ & $(++)$ & $(++)$ \\
Military & $(++)$ & $(+)$ & $(++)$ & $(+)$ & $(++)$ & $(-)$ \\
Clinical & $(++)$ & $(+)$ & $(++)$ & $(-)$ & $(+)$ & $(++)$ \\
Research & $(++)$ & $(++)$ & $(++)$ & $(++)$ & $(++)$ & $(++)$ \\
Industrial & $(++)$ & $(-)$ & $(++)$ & $(-)$ & $(++)$ & $(-)$ \\
Civilian & $(+)$ & $(++)$ & $(+)$ & $(++)$ & $(++)$ & $(+)$ \\
\hline
\end{tabular}

$(++)$ Highly recommended; (+) Moderately recommended; (-) Not recommended; (-) Not possible.

\section{Conclusions}

Out categorization model intends to encompass any exoskeleton in development or on the market. It is a general model and therefore excludes any specific detail referring to any unique exoskeleton. Seventy-five exoskeletons were analyzed to prove the robustness of the categorization model proposed, allowing each exoskeleton to fit into a specific class in each category. More exoskeletons could be added to the list, but these were enough to demonstrate the functionality and future usefulness of the categorization model.

The categorization presented in the article provides an example of a classification system meant to include all exoskeletons made and in progress. This classification is not definitive; their research seeks to further improve upon the recommended model to achieve a standardized method of classifying exoskeletons.

Additionally, a chronology of all the exoskeletons reviewed is provided, separating each one by the phase it is in with respect to its arrival on the market. This helps one to visualize the current state of the exoskeleton field today. Such an image may be used as a reference for future comparison to different points in time. The categorization model may be used to follow exoskeleton development through time until a more robust classification system is developed.

The evolution of the exoskeletons has been long and is far from over. Over the years, new technologies have emerged that have the possibility of being incorporated into exoskeleton design. This review demonstrates how nowadays one may find a great variety of exoskeletons available and in the making. As exoskeletons evolve and are being incorporated into society, they might one day become a part of everyday life.

This systematic review was done to present a new categorization of the exoskeletons and to start a formal standardization, due to the lack of it. Exoskeletons are a part of the near future, so this is the time to set a proper formalization of this topic. 
Furthermore, exoskeletons can aid in many different pathologies; additionally, such devices can help users to avoid long-term health problems, and augment the physical performance of a healthy person. Each exoskeleton relies on the combination of engineering and medicine. Exoskeletons are useful technological developments that have the potential to aid people with varying degrees of mobility.

Supplementary Materials: The following are available at https:/ /www.mdpi.com/2076-3417/11 /1/76/s1, Table S1: Scientometric Indicators. The scientometric indicators were obtained from Scopus ${ }^{\circledR}$ and exported to a datasheet file. On the first sheet, there is a list of all the articles (with their corresponding information) published from 2010 to 2020. On the second sheet are the authors with the most publications from the same dates. Finally, on the third sheet is a list of the institutions with the most publications from the same dates.

Author Contributions: J.A.d.1.T. performed the main review of literature, drafted and wrote the manuscript, and collected the information to create the figures and tables. R.B.-B., R.A.R.-M. and J.I.-R. reviewed the draft and made substantial comments. All authors have read and agreed to the published version of the manuscript.

Funding: This research was supported by Tecnologico de Monterrey and Consejo Nacional de Ciencia y Tecnologia (CONACYT) Mexico, under scholarship number CVU 923079.

Acknowledgments: The authors would like to acknowledge Nathalie Galeano from Vicerrectoria de Investigacion of the Tecnologico de Monterrey for the support in the scientometric studies that were fundamental to complement this work.

Conflicts of Interest: The authors declare no conflict of interest.

\begin{tabular}{|c|c|}
\hline \multicolumn{2}{|c|}{ Abbreviations } \\
\hline The followin & breviations are used in this manuscript: \\
\hline BLEEX & Berkeley Lower Extremity Exoskeleton \\
\hline CAD & Computer-Aided Design \\
\hline SEA & Series Elastic Actuators \\
\hline PID controller & Proportional, Integral and Derivative controller \\
\hline PD controller & Proportional and Derivative controller \\
\hline PI controller & Proportional and Integral controller \\
\hline PSAO & Particularly Shaped Adaptive Oscillator \\
\hline US & United States \\
\hline
\end{tabular}

\section{References}

1. Herr, H. Exoskeletons and orthoses: Classification, design challenges and future directions. J. Neuroeng. Rehabil. 2009, 6, 21. [CrossRef] [PubMed]

2. Andersen, S.O. Chapter 94-Exoskeleton. In Encyclopedia of Insects, 2nd ed.; Resh, V.H., Cardé, R.T., Eds.; Academic Press: San Diego, CA, USA, 2009; pp. 339-342. [CrossRef]

3. Asbeck, A.T.; De Rossi, S.M.; Galiana, I.; Ding, Y.; Walsh, C.J. Stronger, smarter, softer: Next-generation wearable robots. IEEE Robot. Autom. Mag. 2014, 21, 22-33. [CrossRef]

4. McGowan, B. Industrial Exoskeletons: What You're Not Hearing. Available online: https://ohsonline.com/articles/2018/10/01 /industrial-exoskeletons-what-youre-not-hearing.aspx (accessed on 22 November 2019).

5. Dictionary, M.W. Hybrid. Available online: https://www.merriam-webster.com/dictionary/hybrid (accessed on 21 August 2019).

6. Malcolm, P.; Galle, S.; Derave, W.; De Clercq, D. Bi-articular Knee-Ankle-Foot Exoskeleton Produces Higher Metabolic Cost Reduction than Weight-Matched Mono-articular Exoskeleton. Front. Neurosci. 2018, 12, 69. [CrossRef] [PubMed]

7. Van Dijk, W.; Meijneke, C.; van der Kooij, H. Evaluation of the Achilles Ankle Exoskeleton. IEEE Trans. Neural Syst. Rehabil. Eng. 2017, 25, 151-160. [CrossRef]

8. Erdogan, A.; Celebi, B.; Satici, A.C.; Patoglu, V. Assist On-Ankle: A reconfigurable ankle exoskeleton with series-elastic actuation. Auton. Robot. 2017, 41, 743-758. [CrossRef]

9. Dictionary, M.W. Rehabilitation. Available online: https://www.merriam-webster.com/dictionary/rehabilitation (accessed on 21 August 2019).

10. Dictionary, M.W. Assistance. Available online: https://www.merriam-webster.com/dictionary/assistance (accessed on 21 August 2019). 
11. Yagn, N. Apparatus for Facilitating Walking, Running, and Jumping. U.S. Patent 420,179, 28 January 1890.

12. Yagn, N. Apparatus to Facilitate Walking and Running. U.S. Patent 406,328, 2 July 1889.

13. Kelley, L.C. Pedomotor. U.S. Patent 1,308,675, 1 July 1919.

14. Makinson, B.J. Research and Development Prototype for Machine Augmentation of Human Strength and Endurance. Hardiman I Project; Technical Report 196; National Technical Information Service (NTIS): Schenectady, New York, USA; 1971.

15. Mizen, N.J. Powered Exoskeleton Apparatus for Amplifying Human Strength in Response to Normal Body Movements. U.S. Patent 3,449,769A, 17 June 1969.

16. Radulovic, R.; Piera, J.B.; Cassagne, B.; Grossiord, A.; Boruchowitsch, G. The mobile arm support. Prosthetics Orthot. Int. 1980, 4, 101-105. [CrossRef]

17. Chareire, J.L. Mechanical Leg-Propulsion Assistance Device. U.S. Patent 4,872,665, 10 October 1989.

18. Dick, G.J.; Edwards, E.A. Human Bipedal Locomotion Device. U.S. Patent 5,016,869, 21 May 1991.

19. Boldt, K. Three Axis Mechanical Joint for a Power Assist Device. U.S. Patent 5,282,460, 1 February 1994.

20. Zoss, A.; Kazerooni, H.; Chu, A. On the mechanical design of the Berkeley Lower Extremity Exoskeleton (BLEEX). In Proceedings of the 2005 IEEE/RSJ International Conference on Intelligent Robots and Systems, IROS, Edmonton, AB, Canada, 2-6 August 2005; pp. 3132-3139. [CrossRef]

21. Walsh, C.J.; Endo, K.; Herr, H. A Quasi-Passive leg exoskeleton for load-carrying augmentation. Int. J. Humanoid Robot. 2007, 4, 487-506. [CrossRef]

22. Yasuhara, K. Motion Assisting Device. U.S. Patent 2,010,0049,102, 25 February 2010.

23. Sanchez-Villamañan, M.D.C.; Gonzalez-Vargas, J.; Torricelli, D.; Moreno, J.C.; Pons, J.L. Compliant lower limb exoskeletons: A comprehensive review on mechanical design principles. J. Neuroeng. Rehabil. 2019, 16, 55. [CrossRef]

24. He, Y.; Nathan, K.; Venkatakrishnan, A.; Rovekamp, R.; Beck, C.; Ozdemir, R.; Francisco, G.E.; Contreras-Vidal, J.L. An integrated neuro-robotic interface for stroke rehabilitation using the NASA X1 powered lower limb exoskeleton. In Proceedings of the 2014 36th Annual International Conference of the IEEE Engineering in Medicine and Biology Society (EMBC 2014), Chicago, IL, USA, 26-30 August 2014; pp. 3985-3988. [CrossRef]

25. Ren, Y.; Zhang, D. FEXO knee: A rehabilitation device for knee joint combining functional electrical stimulation with a compliant exoskeleton. In Proceedings of the IEEE RAS and EMBS International Conference on Biomedical Robotics and Biomechatronics, Sao Paulo, Brazil, 12-15 August 2014; pp. 683-688. [CrossRef]

26. Aguilar-Sierra, H.; Lopez, R.; Yu, W.; Salazar, S.; Lozano, R. A lower limb exoskeleton with hybrid actuation. In Proceedings of the IEEE RAS and EMBS International Conference on Biomedical Robotics and Biomechatronics, Sao Paulo, Brazil, 12-15 August 2014; pp. 695-700. [CrossRef]

27. Jardim, B.; Siqueira, A.A. Development and analysis of series elastic actuators for impedance control of an active ankle-foot orthosis. J. Braz. Soc. Mech. Sci. Eng. 2014, 36, 501-510. [CrossRef]

28. Rossi, S.; Patanè, F.; Sette, F.D.; Cappa, P. WAKE-up: A Wearable Ankle Knee Exoskeleton. In Proceedings of the 5th IEEE RAS/EMBS International Conference on Biomedical Robotics and Biomechatronics, Sao Paulo, Brazil, 12-15 August 2014; pp. 504-507. [CrossRef]

29. Angold, R.; Harding, N.H.; Kazerooni, H. Exoesqueleto semimotorizado de las extremidades inferiores. European Patent ES2491218T3, 5 September 2014.

30. Galle, S.; Malcolm, P.; Derave, W.; De Clercq, D. Enhancing performance during inclined loaded walking with a powered ankle-foot exoskeleton. Eur. J. Appl. Physiol. 2014, 114, 2341-2351. [CrossRef]

31. Mooney, L.M.; Rouse, E.J.; Herr, H.M. Autonomous exoskeleton reduces metabolic cost of walking. In Proceedings of the 2014 36th Annual International Conference of the IEEE Engineering in Medicine and Biology Society (EMBC 2014), Chicago, IL, USA, 26-30 August 2014; pp. 3065-3068. [CrossRef]

32. Collins, S.H.; Wiggin, M.B.; Sawicki, G.S. Reducing the energy cost of human walking using an unpowered exoskeleton. Nature 2015, 522, 212-215. [CrossRef] [PubMed]

33. Beil, J.; Perner, G.; Asfour, T. Design and control of the lower limb exoskeleton KIT-EXO-1. In Proceedings of the IEEE International Conference on Rehabilitation Robotics, Singapore,11-14 August 2015; pp. 119-124. [CrossRef]

34. Wang, S.; Wang, L.; Meijneke, C.; Van Asseldonk, E.; Hoellinger, T.; Cheron, G.; Ivanenko, Y.; La Scaleia, V.; Sylos-Labini, F.; Molinari, M.; et al. Design and Control of the MINDWALKER Exoskeleton. IEEE Trans. Neural Syst. Rehabil. Eng. 2015, 23, 277-286. [CrossRef] [PubMed]

35. Zhang, C.; Zhu, Y.; Fan, J.; Zhao, J.; Yu, H. Design of a quasi-passive 3 DOFs ankle-foot wearable rehabilitation orthosis. Bio-Med Mater. Eng. 2015, 26, S647-S654. [CrossRef] [PubMed]

36. Cherian, J.J.; Bhave, A.; Kapadia, B.H.; Starr, R.; McElroy, M.J.; Mont, M.A. Strength and Functional Improvement Using Pneumatic Brace with Extension Assist for End-Stage Knee Osteoarthritis: A Prospective, Randomized trial. J. Arthroplast. 2015, 30, 747-753. [CrossRef] [PubMed]

37. Polygerinos, P.; Wang, Z.; Galloway, K.C.; Wood, R.J.; Walsh, C.J. Soft robotic glove for combined assistance and at-home rehabilitation. Robot. Auton. Syst. 2015, 73, 135-143. [CrossRef]

38. Witte, K.A.; Zhang, J.; Jackson, R.W.; Collins, S.H. Design of two lightweight, high-bandwidth torque-controlled ankle exoskeletons. In Proceedings of the IEEE International Conference on Robotics and Automation, Seattle, WA, USA, 26-30 May 2015; pp. 1223-1228. [CrossRef] 
39. Choi, B.; Kim, Y.; Lee, Y.B.; Kim, J. Joint Assembly and Walking Assistance Robot. U.S. Patent US20,150,272,811A1, 1 October 2015.

40. Bortole, M.; Venkatakrishnan, A.; Zhu, F.; Moreno, J.C.; Francisco, G.E.; Pons, J.L.; Contreras-Vidal, J.L. The H2 robotic exoskeleton for gait rehabilitation after stroke: Early findings from a clinical study. J. Neuroeng. Rehabil. 2015, 12, 54. [CrossRef]

41. Zhu, Y.; Cai, X.; Qi, D. Active-Passive Upper Limb Rehabilitation Training Exoskeleton. China Patent CN105597280A, 25 May 2016.

42. Chen, G.; Qi, P.; Guo, Z.; Yu, H. Mechanical design and evaluation of a compact portable knee-ankle-foot robot for gait rehabilitation. Mech. Mach. Theory 2016, 103, 51-64. [CrossRef]

43. Zhang, C.; Liu, G.; Li, C.; Zhao, J.; Yu, H.; Zhu, Y. Development of a lower limb rehabilitation exoskeleton based on real-time gait detection and gait tracking. Adv. Mech. Eng. 2016, 8, 168781401562798. [CrossRef]

44. Wang, J.; Guo, X. Wearable Hand Exoskeleton Rehabilitation Training Robot. China Patent CN105726263A, 19 April 2016.

45. Bujold, A.; Sheitoyan, J.M.; Tremblay, F.; Paquette, P.; Pohl, A.; Forget, S.; Ouanes, A.; Vary, A. Exoskeleton and Method of Using the Same. U.S. Patent 9,492,300B2, 15 November 2016.

46. Kuromiya, Y.; Goto, H.; Nakatsuka, M.; Shimizu, H.; Ishikawa, T. Motion Assist Apparatus. U.S. Patent US9,333,109B2, 10 May 2016.

47. Yin, M.; Xue, H.; Huang, R.; Le, H.; Shen, C.; Shen, L.; Liu, P. Portable and Wearable Exoskeleton upper Limb Robot. China Patent CN105963103A, 28 September 2016.

48. Mooney, L.M.; Herr, H.M. Biomechanical walking mechanisms underlying the metabolic reduction caused by an autonomous exoskeleton. J. Neuroeng. Rehabil. 2016, 13, 4. [CrossRef]

49. Gao, Y.; Xiao, F.; Zhu, Y.; Wang, S.; Zhao, J. Flexible Transmission upper-Limb Exoskeleton Robot for Wearing. China Patent CN105252522A, 20 January 2016.

50. Li, M.; Gu, M.; Zhou, J.; Du, B.; Zhang, L. Lower-Limb-Boosting Exoskeleton Robot. China Patent CN105965483A, 28 September 2016.

51. Li, J.; Wang, D.; Jian, Z.; Li, B. Exoskeletal Rehabilitation Robot for Upper Limbs. China Patent CN105662782A, 15 June 2016.

52. Dai, Y.; Tang, P.; Zhang, X.; Yan, Y.; Zhou, F.; Qin, K.; Deng, C.; Tang, W. Gait-Sensing Flexible Foot Device with Rigidity Self-Adjusting Function. China Patent CN105904439A, 31 August 2016.

53. Chen, N.; Li, Q.; Zhu, G.; Peng, W.; Liu, S. Line Transmission Wearable Type Mechanical Outer Bone. China Patent CN105500343A, 20 April 2016.

54. Seo, K.; Lee, J.; Lee, Y.; Ha, T.; Shim, Y. Fully autonomous hip exoskeleton saves metabolic cost of walking. In Proceedings of the 2016 IEEE International Conference on Robotics and Automation (ICRA), Stockholm, Sweden, 16-21 May 2016; pp. 4628-4635. [CrossRef]

55. García Aracil, N.; Sabater Navarro, J.M.; Fernández Jover, E.; Badesa Clemente, F.J.; Morales Vidal, R.; Díez Pomares, J.A.; Enriquez Urbano, S.C. Modular and Self-Adaptive Robotic Device for Hand Rehabilitation and Use Procedure. Spain Patent ES2558024B1, 10 November 2016.

56. CHOI, H.J.; Na, B.H.; KONG, K.C. Articulated Robot Actuator. WIPO Patent WO2016204441A1, 22 December 2016.

57. Meijneke, C.; Wang, S.; Sluiter, V.; van der Kooij, H. Introducing a Modular, Personalized Exoskeleton for Ankle and Knee Support of Individuals with a Spinal Cord Injury; Springer International Publishing: Cham, Switzerland, 2017; Volume 16, pp. 169-173._28. [CrossRef]

58. O'Neill, C.T.; Phipps, N.S.; Cappello, L.; Paganoni, S.; Walsh, C.J. A soft wearable robot for the shoulder: Design, characterization, and preliminary testing. In Proceedings of the 2017 International Conference on Rehabilitation Robotics (ICORR), London, UK, 17-20 July 2017; pp. 1672-1678. [CrossRef]

59. Huang, C.; Chen, W.; Liu, J.; Zhang, J. Design of a compliant joint actuator for lower-limb exoskeleton robot. In Proceedings of the 2017 12th IEEE Conference on Industrial Electronics and Applications (ICIEA), Siem Reap, Cambodia, 18-20 June 2017; pp. 1522-1527. [CrossRef]

60. Angold, R.; Fleming, N. Exoskeleton and Method of Increasing the Flexibility of an Exoskeleton Hip Joint. U.S. Patent 9,604,369B2, 28 March 2017.

61. Choi, W.; Won, J.; Lee, J.; Park, J. Low stiffness design and hysteresis compensation torque control of SEA for active exercise rehabilitation robots. Auton. Robot. 2017, 41, 1221-1242. [CrossRef]

62. Zhang, J.; Hong, J.; Li, M.; Wang, H. EMG Controlled Air-Operated Soft Body Rehabilitative Mechanical Hand. China Patent CN106309083A, 1 January 2017.

63. Dao, Q.T.; Hagiwara, M.; Yamamoto, S.I. Design and Evaluation of the Lower-limb Robotic Orthosis for Gait Rehabilitation Actuated by Pneumatic Artificial Muscle. In Proceedings of the 2nd International Conference on Biomedical Signal and Image Processing (ICBIP 2017), Kitakyushu, Japan, 23-25 August 2017; ACM Press: New York, NY, USA, 2017; pp. 85-89. [CrossRef]

64. Yoon, S.J.; Kwon, Y.D.; Roh, K.S.; Ahn, S.H. Robot and Control Method Thereof. U.S. Patent 9,566,706B2, 14 February 2017.

65. Dos Santos, W.M.; Caurin, G.A.; Siqueira, A.A. Design and control of an active knee orthosis driven by a rotary Series Elastic Actuator. Control Eng. Pract. 2017, 58, 307-318. [CrossRef]

66. Julin, A.; Hughes, M. Ball Screw and Tensile Member Exoskeleton Joint Actuation Device. European Patent EP3243606A1, 15 November 2017. 
67. Grygorowicz, S.; Riglet Epouse Baptiste, A.; Charmoille, S.; Perrin, A.; Lelogeais, Y. Exoskeleton with Telescopic Legs at the Rear. WIPO Patent WO2017121971A1, 20 July 2017.

68. Soltani-Zarrin, R.; Zeiaee, A.; Eib, A.; Langari, R.; Robson, N.; Tafreshi, R. TAMU CLEVERarm: A novel exoskeleton for rehabilitation of upper limb impairments. In Proceedings of the 2017 International Symposium on Wearable Robotics and Rehabilitation (WeRob), Houston, TX, USA, 5-8 November 2017; IEEE: Houston, TX, USA, 2017; pp. 1-2. [CrossRef]

69. Zhang, J.; Fiers, P.; Witte, K.A.; Jackson, R.W.; Poggensee, K.L.; Atkeson, C.G.; Collins, S.H. Human-in-the-loop optimization of exoskeleton assistance during walking. Science 2017, 356, 1280-1283. [CrossRef] [PubMed]

70. Klassen, J.B. Exoskeleton Suit with Hand Control to Enable Walking. U.S. Patent 20,170,181,916A1, 29 June 2017.

71. Pina, D.S.; Fernandes, A.A.; Jorge, R.N.; Gabriel, J. Designing the mechanical frame of an active exoskeleton for gait assistance. Adv. Mech. Eng. 2018, 10, 168781401774366. [CrossRef]

72. Schrade, S.O.; Dätwyler, K.; Stücheli, M.; Studer, K.; Türk, D.A.; Meboldt, M.; Gassert, R.; Lambercy, O. Development of VariLeg, an exoskeleton with variable stiffness actuation: First results and user evaluation from the CYBATHLON 2016. J. Neuroeng. Rehabil. 2018, 15, 18. [CrossRef] [PubMed]

73. Van Engelhoven, L.; Kazerooni, H. Apparatus for Human Arm Supporting Exoskeleton. U.S. Patent 10,124,485B2, 13 November 2018.

74. Dalley, S.A.; Hartigan, C.; Kandilakis, C.; Farris, R.J. Increased Walking Speed and Speed Control in Exoskeleton Enabled Gait. In Proceedings of the 2018 7th IEEE International Conference on Biomedical Robotics and Biomechatronics (Biorob), Enschede, The Netherlands, 26-29 August 2018; pp. 689-694. [CrossRef]

75. Angold, R.; Lubin, J.; Solano, M.; Paretich, C.; Mastaler, T. Exoesqueleto y método Para Proporcionar un par de Asistencia a un Brazo de un Usuario. Spain Patent ES2690989T3, 23 November 2018.

76. Graf, E.S.; Pauli, C.; Erkens, L.; Brinks, G.; O'Sullivan, L.; Wirz, M.; Stadler, K.S.; Ortiz, J.; Bauer, C.M.; Power, V.; et al. Basic functionality of a prototype wearable assistive soft exoskeleton for people with gait impairments. In Proceedings of the 11th PErvasive Technologies Related to Assistive Environments Conference on-PETRA '18, Athens, Greece, 16-18 July 2008; ACM Press: New York, NY, USA, 2018; pp. 202-207. [CrossRef]

77. Harib, O.; Hereid, A.; Agrawal, A.; Gurriet, T.; Finet, S.; Boeris, G.; Duburcq, A.; Mungai, M.E.; Masselin, M.; Ames, A.D.; et al. Feedback Control of an Exoskeleton for Paraplegics: Toward Robustly Stable, Hands-Free Dynamic Walking. IEEE Control Syst. 2018, 38, 61-87. [CrossRef]

78. Lee, S.; Kim, J.; Baker, L.; Long, A.; Karavas, N.; Menard, N.; Galiana, I.; Walsh, C.J. Autonomous multi-joint soft exosuit with augmentation-power-based control parameter tuning reduces energy cost of loaded walking. J. Neuroeng. Rehabil. 2018, 15, 66. [CrossRef]

79. Chapman, T.W. Exoskeleton System for Load Carrying. U.S. Patent US10,165,847B2, 1 January 2019.

80. Geffard, F.; Ponsort, D. Lower Limb of an Exoskeleton with Low Power Consumption. WIPO Patent WO2019057797A1, 28 March 2019.

81. Maddry, C.J. Pneumatic Electromyographic Exoskeleton. U.S. Patent US10,231,851B2, 19 March 2019.

82. Sankai, Y. Wearing-Type Movement Assistance Device. U.S. Patent US10,265,857B2, 23 April 2019.

83. Kim, J.; Lee, G.; Heimgartner, R.; Arumukhom Revi, D.; Karavas, N.; Nathanson, D.; Galiana, I.; Eckert-Erdheim, A.; Murphy, P.; Perry, D.; et al. Reducing the metabolic rate of walking and running with a versatile, portable exosuit. Science 2019, 365, 668-672. [CrossRef]

84. Pruess, A.; Meadows, C.; Amundson, K.; Angold, R.; Lubin, J.; Solano, M.; Mastaler, T.; Fleming, N.; Sweeney, M. Human Exoskeleton Devices for Heavy Tool Support and Use. U.S. Patent US10,327,536B2, 25 June 2019.

85. Doyle, M.C. Heavy Capacity Arm Support Systems. U.S. Patent US10,208,893B2, 19 February 2019.

86. ReWalk. ReWalk ${ }^{\mathrm{TM}}$ Personal 6.0. Available online: https://rewalk.com/rewalk-personal-3/ (accessed on 19 September 2019).

87. Yokneam Ilit, I. ReWalk Robotics Launches ReWalk 6.0: The Company's Sixth Generation Personal System for Home \& Community Use. Available online: https:/ / tinyurl.com/ReWalk-6 (accessed on 20 August 2019).

88. Dephy. Dephy ExoBoot. Available online: http://dephy.com/products/ (accessed on 2 August 2019).

89. Farris, R.; Clausen, M.; Wilson, E. Wearable Robotic Device. U.S. Patent US20,170,049,659A1, 23 February 2017.

90. Indego. Indego Therapy Resources. Available online: http://www.indego.com/indego/en/Indego-Therapy (accessed on 23 September 2019).

91. Gormley, A. Parker Releases New Indego Therapy Exoskeleton. Available online: https://investors.parker.com/news-releases/ news-release-details / parker-releases-new-indego-therapy-exoskeleton (accessed on 12 September 2019).

92. Doyle, M.C. Adaptive Arm Support Systems and Methods for Use. U.S. Patent US9,737,374B2, 22 August 2017.

93. Levitate Technologies Inc.. AIRFRAME ${ }^{\circledR}$. Available online: https://www.levitatetech.com/airframe/ (accessed on 24 September 2019).

94. Lockheed Martin. New Lockheed Martin Exoskeleton Helps Soldiers Carry Heavy Gear. Available online: https://tinyurl.com/ LockHeed-Martin (accessed on 1 August 2019).

95. ekso Bionics. eksoVest. Available online: https://eksobionics.com/eksoworks/eksovest/ (accessed on 22 October 2019).

96. Ford Media Center. Ford Pilots New Exoskeleton Technology to Help Lessen Chance of Worker Fatigue, Injury. Available online: https:/ / media.ford.com/content/fordmedia/fna/us/en/news/2017/11/09/ford-exoskeleton-technology-pilot.html (accessed on 22 October 2019). 
97. ekso Bionics. eksoNR. Available online: https://eksobionics.com/eksohealth/ (accessed on 13 August 2019).

98. Spring Loaded. Levitation 2. Available online: https://springloadedtechnology.com/product/levitation-knee-brace/ (accessed on 16 September 2019).

99. Williams, C. Spring Loaded Bionic Knee Brace Leaps Closer to Mass Production; Technical Report; CBC News: Halifax, NS, Canada, 2016.

100. ReWalk. The ReStore ${ }^{\mathrm{TM}}$ Soft Exo-Suit. Available online: https:/ / rewalk.com/restore-exo-suit/ (accessed on 19 September 2019).

101. Smith, F.; Olivier, M.; Colvin, G. Tunable Actuator Joint Modules Having Energy Recovering Quasi-Passive Elastic Actuators for Use within a Robotic System. European Patent EP3326760A1, 30 May 2018.

102. Martindale, K. The Guardian ${ }^{\circledR} \mathrm{XO}^{\circledR}$ Robotic Exoskeleton Takes the Tech Industry by Storm. Available online: https://tinyurl. com/Guardian-XO (accessed on 25 March 2020).

103. Heo, P.; Gu, G.M.; Lee, S.j.; Rhee, K.; Kim, J. Current hand exoskeleton technologies for rehabilitation and assistive engineering. Int. J. Precis. Eng. Manuf. 2012, 13, 807-824. [CrossRef]

104. Maciejasz, P.; Eschweiler, J.; Gerlach-Hahn, K.; Jansen-Troy, A.; Leonhardt, S. A survey on robotic devices for upper limb rehabilitation. J. Neuroeng. Rehabil. 2014, 11,3. [CrossRef]

105. Miller, L.; Zimmermann, A.; Herbert, W. Clinical effectiveness and safety of powered exoskeleton-assisted walking in patients with spinal cord injury: Systematic review with meta-analysis. Med. Devices Evid. Res. 2016, 9, 455. [CrossRef]

106. Manna, S.K.; Dubey, V.N. Comparative study of actuation systems for portable upper limb exoskeletons. Med. Eng. Phys. 2018, 60, 1-13. [CrossRef] [PubMed]

107. Gopura, R.; Bandara, D.; Kiguchi, K.; Mann, G. Developments in hardware systems of active upper-limb exoskeleton robots: A review. Robot. Auton. Syst. 2016, 75, 203-220. [CrossRef]

108. Voilque, A.; Masood, J.; Fauroux, J.; Sabourin, L.; Guezet, O. Industrial Exoskeleton Technology: Classification, Structural Analysis, and Structural Complexity Indicator. In Proceedings of the 2019 Wearable Robotics Association Conference (WearRAcon), Scottsdale, AZ, USA, 25-27 March 2019; IEEE: Scottsdale, AZ, USA, 2019; pp. 13-20. [CrossRef]

109. Young, A.J.; Ferris, D.P. State of the art and future directions for lower limb robotic exoskeletons. IEEE Trans. Neural Syst. Rehabil. Eng. 2017, 25, 171-182. [CrossRef] [PubMed] 